Portland State University

PDXScholar

\title{
Medical Faculty Engagement in Curricular Revisions: an Inquiry into Individual and Organizational Factors that Support Participation
}

Tomoko Tanikawa

Portland State University

Follow this and additional works at: https://pdxscholar.library.pdx.edu/open_access_etds

Part of the Curriculum and Instruction Commons, Higher Education Commons, and the Medical Education Commons

Let us know how access to this document benefits you.

\section{Recommended Citation}

Tanikawa, Tomoko, "Medical Faculty Engagement in Curricular Revisions: an Inquiry into Individual and Organizational Factors that Support Participation" (2020). Dissertations and Theses. Paper 5422. https://doi.org/10.15760/etd.7295

This Dissertation is brought to you for free and open access. It has been accepted for inclusion in Dissertations and Theses by an authorized administrator of PDXScholar. Please contact us if we can make this document more accessible: pdxscholar@pdx.edu. 
Medical Faculty Engagement in Curricular Revisions: An Inquiry into Individual and Organizational Factors that Support Participation

by

Tomoko Tanikawa

A dissertation submitted in partial fulfillment of the requirements for the degree of

Doctor of Education

in

Educational Leadership: Postsecondary Education

Dissertation Committee:

Christine Cress, Chair

Andrew Job

Moti Hara

Kevin Kecskes

Portland State University

2020 


\begin{abstract}
In efforts to facilitate the education of highly qualified and best-prepared medical professionals, many medical schools are either planning for or engaging in curriculum revisions including a complete overhaul of the curricular structure, academic and medical content, and pedagogical delivery modalities. To be effective, such changes require faculty buy-in, participation, engagement, and innovation. Unfortunately, despite medical schools' efforts to support faculty involvement in curricular revision, a range of reactions exist, including resistance. Thus, understanding the interactions between individual faculty attitudes and behaviors toward organizational initiatives and structural support is critical in advancing the educational mission of medical schools. Based on Rogers' variables determining the rate of adoption of innovation, this study addressed the question: What factors foster medical education faculty to adopt and advance curricular changes? Specifically, this study explored both the intrinsic and extrinsic factors that contribute to medical faculty engagement in curricular transformation. The study found that intrinsic motivation factor, specifically congruence of the innovation with their preexisting belief played a key role in the faculty participants' motivation to participate in the new curriculum and adopt learner-centered active learning methods. In addition, simplicity of the active learning methods was found to be a motivational factor in contrary to the one that was perceived as too complex, time-consuming and difficult to implement despite the administration's effort to provide faculty development. The study also found that norms and attitude toward teaching mission within their respective
\end{abstract}


departments contributed to the faculty participants' motivation to participate in the curriculum revision. 
Table of Contents

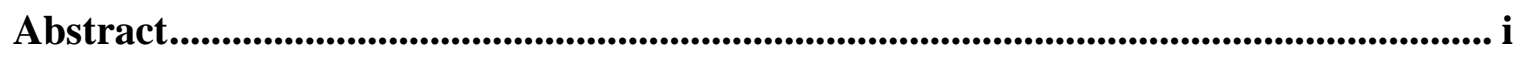

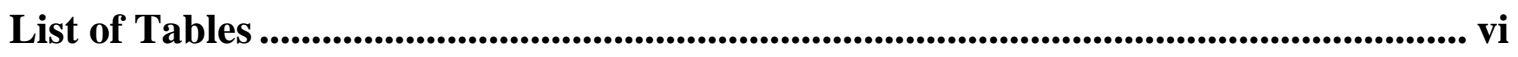

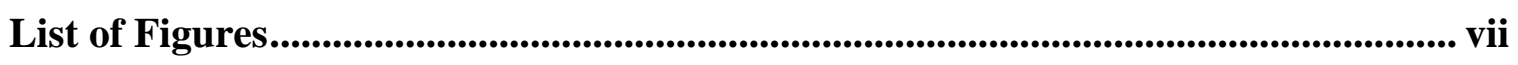

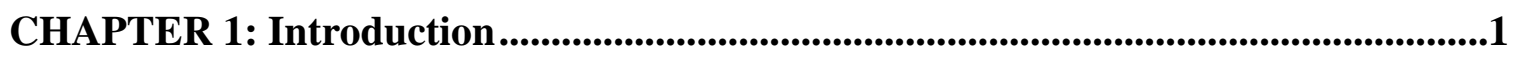

U.S. Medical Education ...................................................................................... 1

Medical Education Curriculum Transformation ......................................................... 3

Faculty Roles in Curriculum Transformation ......................................................... 5

Pedagogical Change in Medical Education ......................................................... 7

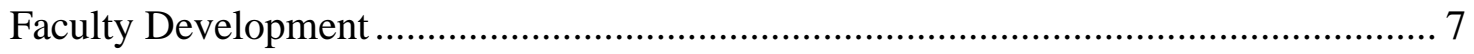

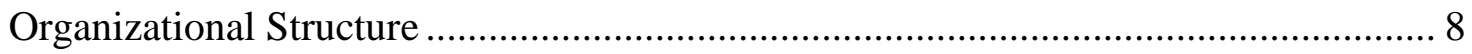

Factors that Facilitate Faculty Engagement in Curricular Revision .......................... 8

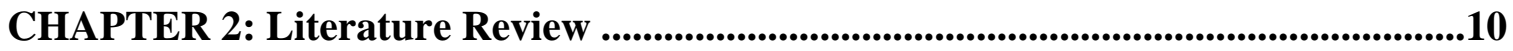

The Current State of U.S. Health Care .................................................................... 10

Rogers' Diffusion of Innovation Model ........................................................... 12

Intrinsic Factors: Perceived Attributes of Innovations .......................................... 14

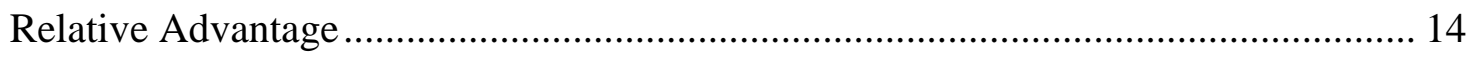

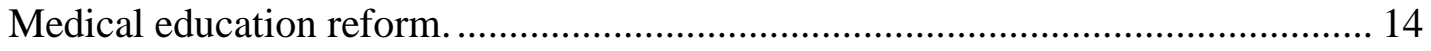

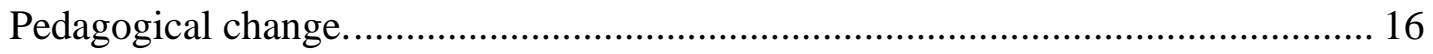

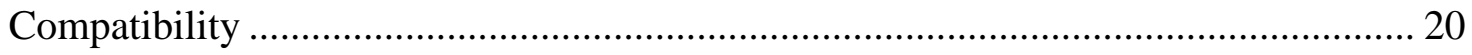

Historical formation of medical education in the United States............................ 20

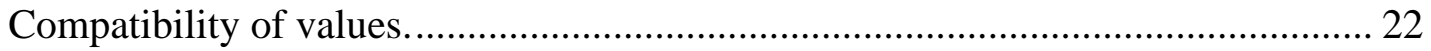

Compatibility with past experiences in the role of teacher................................. 23

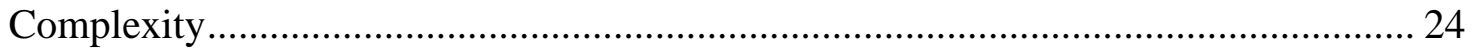

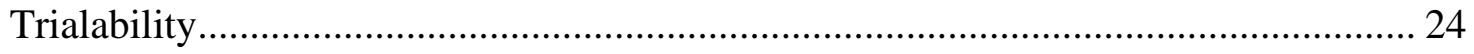

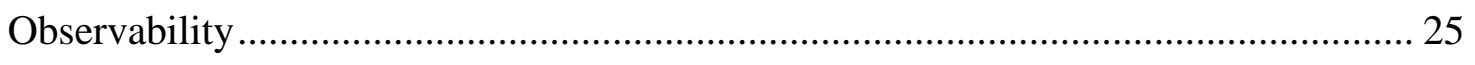

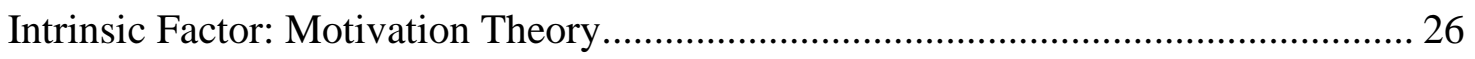

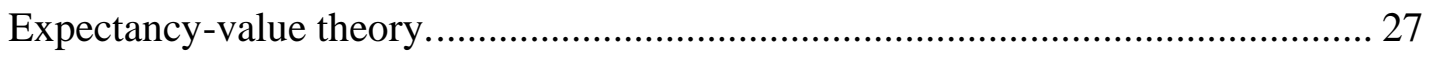

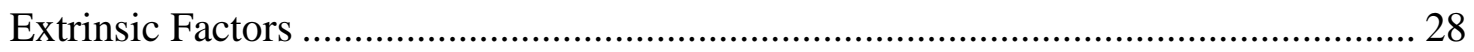




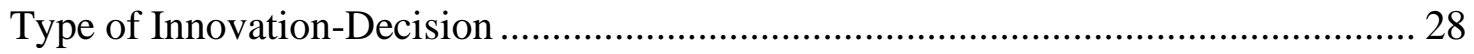

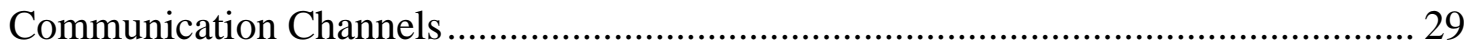

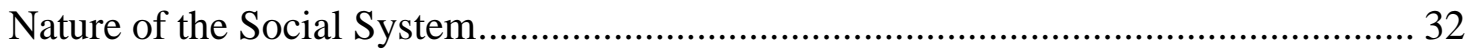

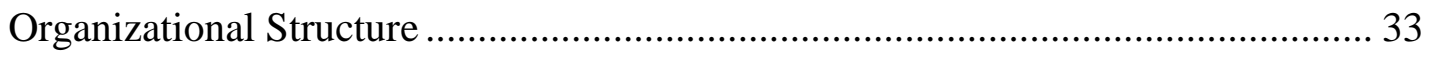

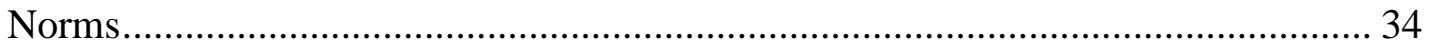

Extent of Change Agents' Promotion Efforts ........................................................ 34

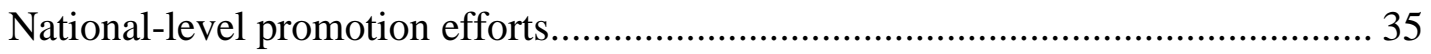

Institution-level promotion efforts................................................................. 38

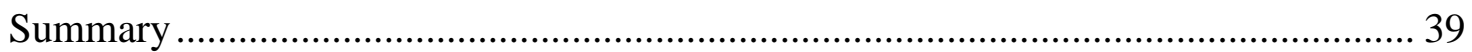

CHAPTER 3: Research Methodology ............................................................................41

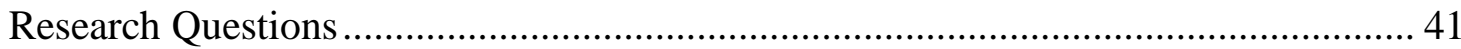

Narrative Analysis Method ............................................................................ 42

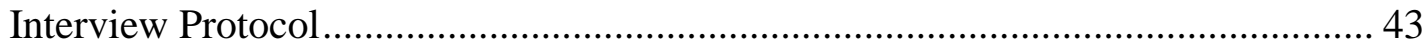

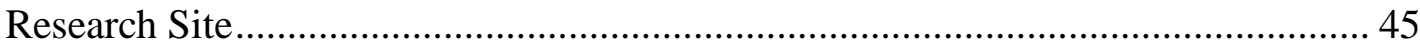

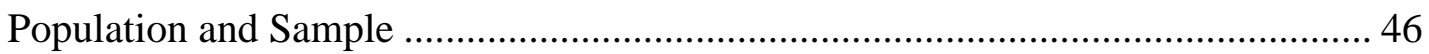

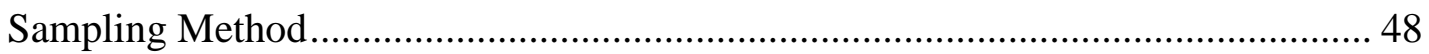

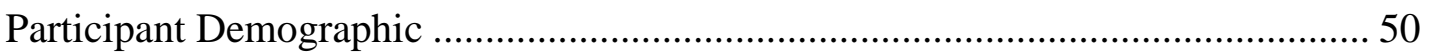

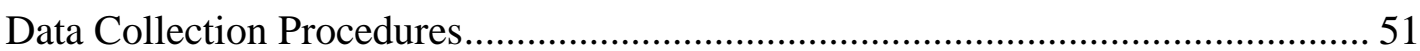

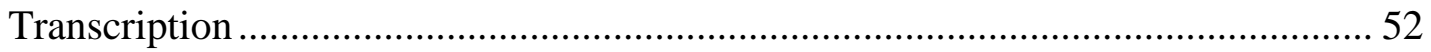

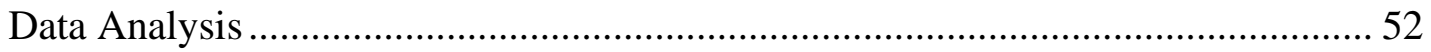

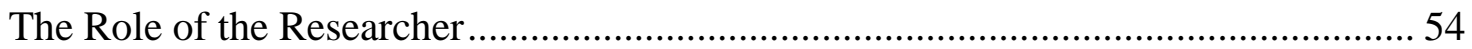

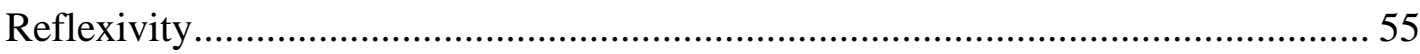

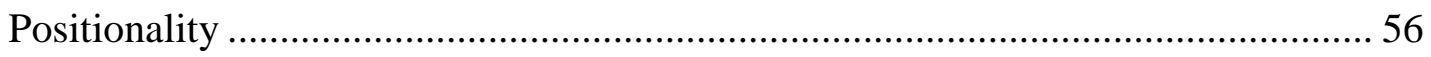

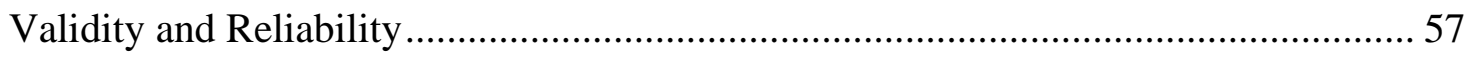

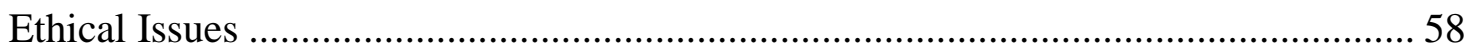

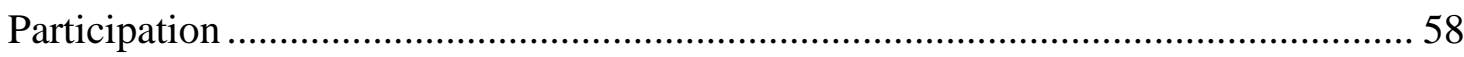

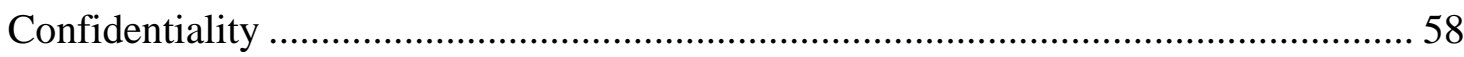

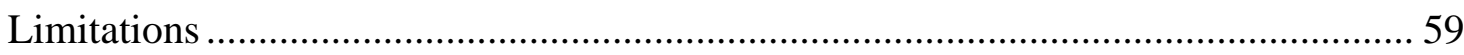

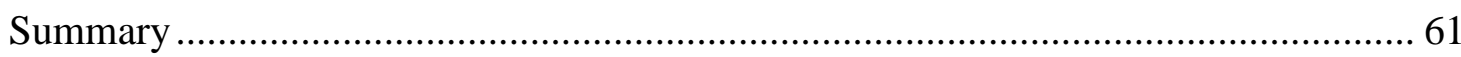

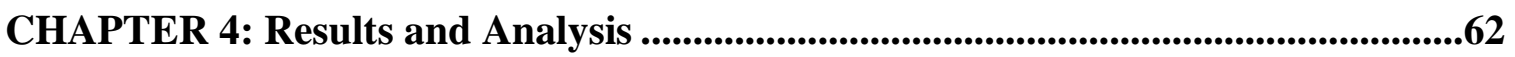

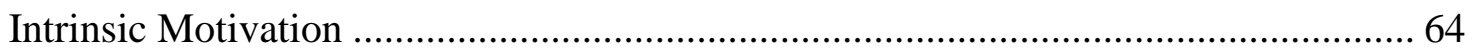

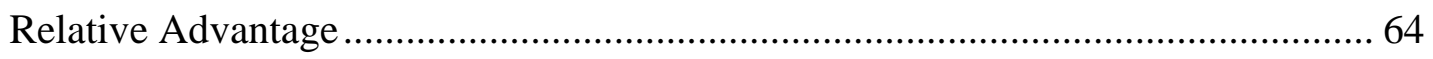

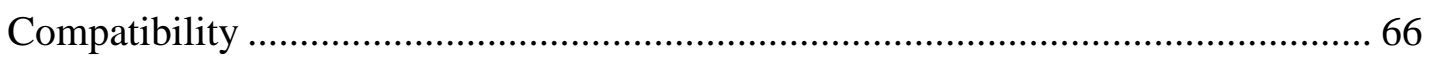




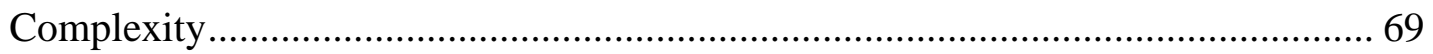

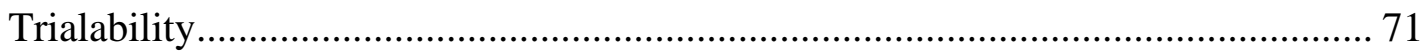

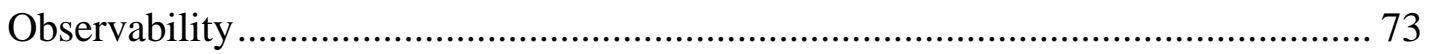

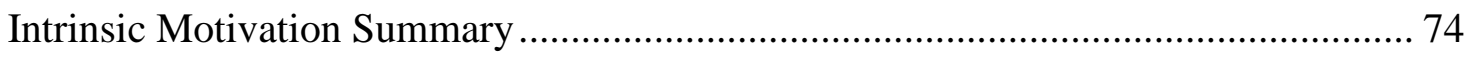

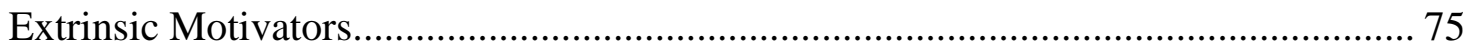

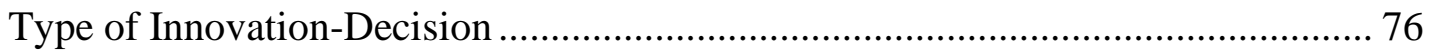

Communication Channels ........................................................................... 78

Nature of the Social System........................................................................... 80

Extent of Change Agent's Promotion Efforts .................................................... 81

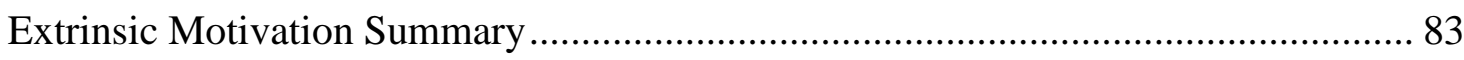

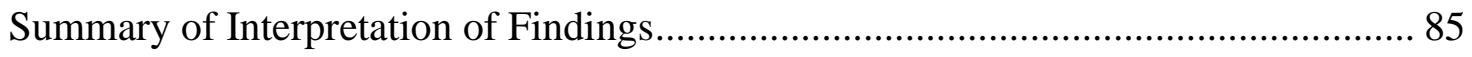

CHAPTER 5: Discussion and Conclusion ........................................................................91

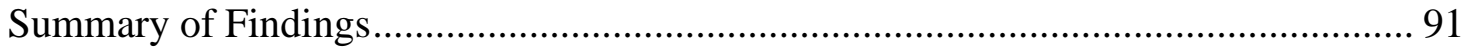

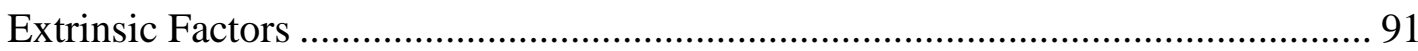

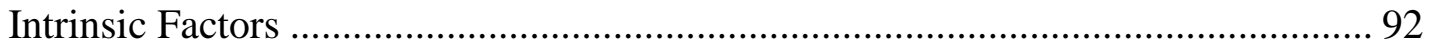

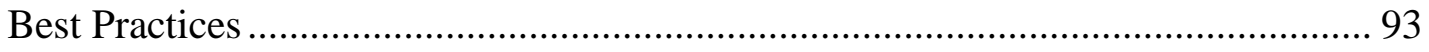

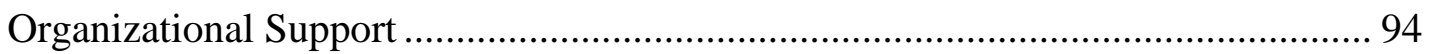

Implications and Recommendations to Change Agents ....................................... 95

Recommendation 1: Transition Management and Communication ........................ 95

Recommendation 2: Identification of Early Adopters ........................................ 97

Recommendation 3: Faculty Development....................................................... 98

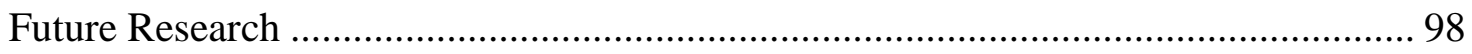

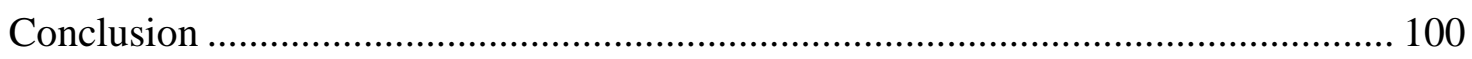

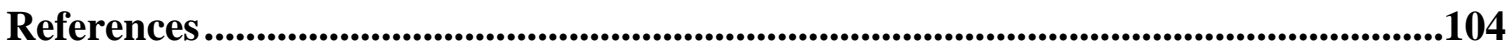

Appendix A: Development of Interview Questions....................................................122

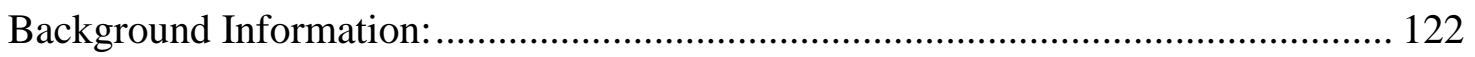

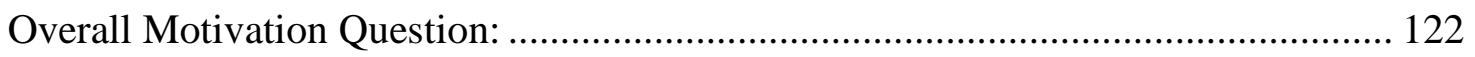

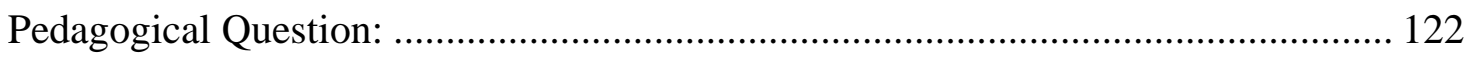

Adaptation of Rogers' Model: ......................................................................... 122

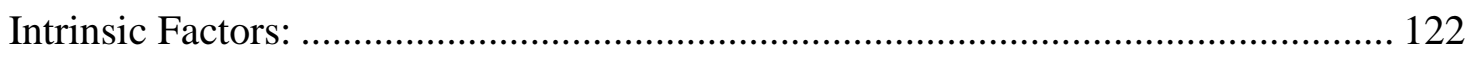

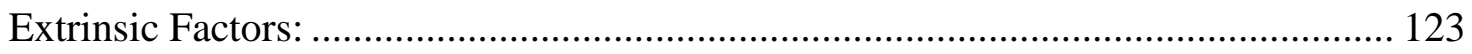

Appendix B: Interview Questions..................................................................................125

Appendix C: Consent to Participate in Research ..........................................................127 


\section{List of Tables}

Table 1: Background Information of Participants .............................................51

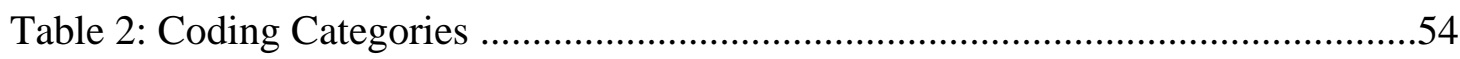




\section{List of Figures}

Figure 1: Life Expectancy and Health Spending Per Capita ......................................11

Figure 2: Variables Determining the Rate of Adoption of Innovations .........................13

Figure 3: Thematic Codes and Categories ..........................................................53 


\section{CHAPTER 1: Introduction}

According to the World Health Organization, the U.S. health-care system ranked 37th in the world (World Health Statistics, 2015) despite having the second highest health expenditure as percentage of gross domestic product (World Health Statistics, 2019). Among eleven industrial nations, the U.S. received the worst overall ranking (Common Wealth, 2014). Moreover, estimated deaths in hospitals that are linked to preventable harms are reported to be 210,000 (James, 2013) to upward of 400,000 (Wiklund, Dwyer, \& Davis, 2015).

Inarguably, there is a problem with the U.S. health-care system. The problem is multi-layered and complex; to name a few, components that perpetuate the subpar healthcare system include resource allocation, the economics of health care, the historical formation of the U.S. health-care system, health policy, and inadequate medical education. In the interest of long-standing goals for improving the health-care system, national organizations such as the American Medical Association (AMA) and Association of American Medical Colleges (AAMC) are calling for transformation in medical education.

\section{U.S. Medical Education}

Attaining a medical school degree is the first phase in becoming a medical professional in the United States, followed by graduate medical education (i.e. residency program) and continuing medical education (i.e. physician's education). According to Kassebaum (1992), "medical education is just one part of the great medical structure in the United States which begins with students coming up and men going out into practice" 
(p. 87). Per the accreditation body, Liaison Committee on Medical Education, medical schools must include at least 130 weeks of instruction. The majority of medical schools in the United States award the MD degree. Upon graduation, students enter residency programs. The length of residency programs varies from three to six years depending on medical specialties. Upon completion of residency programs, and throughout their career, physicians are required to participate in continuing education in order to maintain their medical licenses.

The current model of medical school education is based on the 1910 Flexner Report, which embraced scientific knowledge (Duffy, 2011). For over 100 years, medical schools maintained the Flexner's educational framework and structure (Beck, 2004). However, as the landscape of U.S. health care changes and awareness rises regarding deficiencies in the current health-care system and health delivery such as high costs, poor safety records, and poor health outcomes (Osborne \& Fields, 2014; Woolf \& Aron, 2013), medical schools and residency programs are taking steps to modify their educational frameworks. To that end, national organizations including various associations and accreditation agencies have been spearheading efforts to change the way medical students are educated. Changes include the implementation of competency-based education, which requires a paradigm shift from structured, time-based, process-based education to outcome driven education (Carraccio, Wolfsthal, Ferrentz, Englander, \& Martin, 2002) and active learning, that is, "any learning activity engaged in by students in a classroom other than listening passively to an instructor's lecture" (Faust \& Paulson, 
1998, p. 4), and adding emerging science content areas such as health systems science or patient safety (Kalra, 2011).

\section{Medical Education Curriculum Transformation}

Such bold pedagogical goals for improving medical education require major curricular transformation. Many medical schools are either planning for or engaging in curriculum revisions; some are experiencing a complete overhaul of the curriculum structure - pedagogy as well as content. While these revisions are intended to improve the quality of medical education and better prepare students to provide high-quality health care, the actual processes of curricular transformation and implementation of new curricula can cause dissonance among faculty who have enjoyed autonomy (Brownell \& Tanner, 2012). Moreover, curriculum transformations require faculty buy-in, active participation, engagement, and innovation. Despite administrations' efforts to minimize resistance, a spectrum of faculty reactional behaviors occur ranging from early, motivated adaptation of new curriculum to negative ones such as disengagement, disidentification, and disenchantment (Appelbaum, Leblanc, \& Shapiro, 1998). Faculty who are disengaged may initially seem harmless to the desired outcome, but as their lack of interest and initiatives become apparent, they can adversely affect the change process and its implementation. Disidentification is another reaction to change, which may occur, for instance, when a seasoned faculty member who has served as a course director in a former curriculum for many years feels threatened by a new curriculum; losing security, sense of ownership, and self-worth may put faculty into a vulnerable state.

Disenchantment is often the most visible to administrators. Faculty may try to sabotage 
new curriculum by badmouthing, spreading rumors, or creating coalitions to resist changes. Visible or not, these negative behavioral reactions pose challenges to the administrations. (Banta \& Palomba, 2014; Repetto \& Trentin, 2011; Swilky, 1992).

In contrast, there are motivated faculty members who embrace the change, take initiatives to seek and implement curricular innovation, actively engage in fact-finding about pedagogical strategies, seek help to lessen ambiguity and uncertainty in their academic content and teaching approaches, and find ways to be integral contributors and members of those revising the medical education curriculum. Rogers (2003) asserts that faculty engagement in curricular revision efforts can be categorized on a continuum including those who are considered early adopters. According to Rogers, faculty who are early adopters decrease "uncertainty about a new idea by adopting it, and then conveying a subjective evaluation of the innovation to near peers through interpersonal networks" (p. 283). Although Rogers distinguishes early adopters from innovators (i.e. risk-takers who play roles in importing and launching new ideas from outside of the system's boundaries), for the purpose of this study, the two categories will be collapsed and classified as early adopters. In sum, these are the engaged, fully committed, and concerned faculty who are willing to create content, courses, and programs that facilitate students' academic success. Indeed, the research literature is clear that faculty commitment to and engagement in curricular enhancement is directly related to the educational and professional success of a program's students and graduates. 


\section{Faculty Roles in Curriculum Transformation}

Hendrickson and Lane (2013) state that faculty play a key role in "fulfilling the institution's mission of the advancement of knowledge and education of citizens" ( $\mathrm{p}$. 311). Studies suggest that faculty have a direct influence on students' success. For example, according to Tinto (1993), among undergraduate college students, the level of student engagement is highly associated with purposeful student-faculty contact. Studentfaculty interaction was also positively associated with academic outcomes and degree attainment.

Similarly, the ability of faculty to deliver high-quality instruction affects learners' motivation. Sogunro (2015) conducted a study on motivating factors for adult learners and concluded that there are eight motivating factors: quality curriculum, quality instruction, relevance and pragmatism, interactive classroom and effective management, progressive assessment and timely feedback, conducive learning environment, selfdirectedness, and academic advising. Among these eight factors, quality of instruction, quality of curriculum, and relevance and pragmatism ranked highest in terms of influence on learner motivation - three factors over which faculty have direct control. According to Sogunro's study, the quality of curriculum affects learners' satisfaction level, thus influencing their learning.

Furthermore, Williams and Williams (2011) argue that there are five key ingredients which impact student motivation: student, teacher, content, method/process, and environment. Kuh (2008) stated that the classroom experience may have significant effects on multiple aspects of student growth and satisfaction. Faculty play an integral 
role in learners' motivation and learning by creating and providing well-designed curriculum and by contributing to the shaping of other influencing factors.

However, today's faculties face many challenges in addition to effective curriculum. Faculty roles have expanded to include teaching, mentoring, advising, engaging in scholarly works, developing programs, and participating in academic governance. Medical education faculty may also have patient clinical loads to balance.

In the last 30 years, expectations of faculty scholarly productivity have increased as well (e.g. research demands, publishing requirements, various scholarly works, and grant/resource acquisition expectations) (Berry, 2005; Papp and Aron, 2000). Faculty, more than ever, are under pressure to produce. In the era of decreased National Institutes of Health (NIH) funding, researchers, including medical education faculty are under tremendous stress to sustain their labs (Garrison \& Deschamps, 2014). According to the Federation of American Societies for Experimental Biology (2014), "in 12 of the past 13 years, NIH funding has either been cut or has failed to outpace rising costs. As a result, in constant dollars, the NIH budget remains more than 22 percent below the Fiscal Year 2003 level" (p. 1).

Curriculum transformation adds to the challenges and expectations to faculties that already face significant pressure to perform with shrinking resources and high demands for productivity. However, curriculum transformation efforts depend upon faculty involvement, and some have indeed risen to the challenges as early adaptors of new curriculum, taking on roles as planners, developers, and implementers and 
employing new pedagogical approaches to their instruction to promote learner-centered curricula (Green, 2007; Keating, 2014).

\section{Pedagogical Change in Medical Education}

One of the major components of curriculum transformation that directly affect

faculty (and learners as well) is pedagogical change. As a part of the national movement to improve medical education, many medical schools are changing their pedagogical approach; specifically, they are moving away from the transmission of knowledge to a more holistic, active, learner-centered approach. Oakley, Felder, Brent and Elhajj (2004) point out the numerous benefits of incorporating small-group learning, such as retention, achievement of higher grades, and improvement of communication skills. Although the design of active learning methods has been documented by many medical schools, reliance on the lecture format persists (Ludmerer, 2004; Prober \& Heath, 2012). The pervasiveness of such traditional learning approaches highlights the need for educational organizations to offer faculty alternative pedagogical approaches.

\section{Faculty Development}

With pedagogical changes, developing faculty competency and capability to deliver new curricular content is essential. Wilkerson and Irby (1998) define faculty development "as a tool for improving the educational vitality of our institution" (p. 390). Changing the structure, content, instructional delivery and assessment methods directly affect faculty. As aforementioned, the quality of instruction and teachers are essential components that affect learner motivation. Curriculum reform without sufficient, efficient, effective, and appropriate faculty development is therefore at a major 
disadvantage in terms of successful implementation. As such, organizational structures and supports are critical to engendering faculty knowledge and motivations for engaging in curricular revision efforts.

\section{Organizational Structure}

Organizational structures allow communication to flow. Rogers (2003) defined communication "as the process by which participants create and share information with one another in order to reach a mutual understanding" (p. 18). Shared vision is one of the key components of successful planning and implementation of curriculum transformation. The organizational model can hinder or promote communication flow.

\section{Factors that Facilitate Faculty Engagement in Curricular Revision}

Medical education, like other educational institutions, must be responsive to contemporary challenges in order to best prepare its students and graduates. Other issues such as increased competition for qualified candidates, shifts in educational philosophies about the creation and transmission of knowledge (Emes \& Cleveland-Innes, 2003), new patterns in learner demographics, economic changes, (Brown \& Nelson, 2003; Veale et al., 2014), and adaptation to educational technology (Crompton, 2004) are some of the multiple reasons driving medical school curricular changes across the educational spectrum. In short, changing health-care models and delivery methods are driving forces for curriculum revisions (Conger, Baldwin, Abegglen, \& Callister, 1999). Still, no matter what rationales institutions and administrations hold, faculty buy-in and participation are essential in planning, implementing, and delivering effective curriculum transformation. Thus, understanding the interactions between individual faculty member attitudes and 
behaviors and organizational initiatives and structural supports is critical to advancing the educational mission of medical schools. To better understand possible individual and organizational factors that influence faculty participation in curricular transformation, relevant literature is reviewed in the next chapter. 


\section{CHAPTER 2: Literature Review}

In this chapter, the current state of U.S. health care will be detailed to illustrate and emphasize needs for systematic change including the education of future physicians. Throughout this chapter, Rogers' (2003) five variables determining the rate of adoption of innovation will be used as a framework to examine intrinsic (i.e. individual faculty perspectives) and extrinsic (i.e. external elements including organizational) factors that contribute to medical faculty engagement in curricular revisions.

The purpose of this study is to explore intrinsic and extrinsic factors of faculty early adopters because successful implementation of curricular changes depends on their active participation. Multiple factors intertwine and affect faculty members' attitudes, decisions, and behaviors in adopting new curriculum and pedagogical approaches. Thus, it is essential to explore and examine factors that promote and facilitate these attitudes and behaviors.

\section{The Current State of U.S. Health Care}

The high cost of U.S. health care has been discussed in numerous literatures (e.g. Emanuel et al., 2012; Sutherland, Fisher, \& Skinner, 2009). Berwick and Hackbarth (2012) identified six categories of waste: overtreatment, failures of care coordination, failures in execution of care processes, administrative complexity, pricing failures, and fraud and abuse. Despite the high cost, Woolf and Aron (2013) point out that compared to 17 other industrialized nations, the U.S. had the highest probability of children dying before age 5. When the Institute of Medicine reported the number of deaths in U.S. hospitals due to medical errors to be between 44,000 and 98,000 per year, it caught not 
only public, but government attention, which urged changes in regulations, the system, and safety programs (Leape, 2000). Life expectancy is also the lowest among industrialized nations despite the highest health spending per capita (see Figure 1).

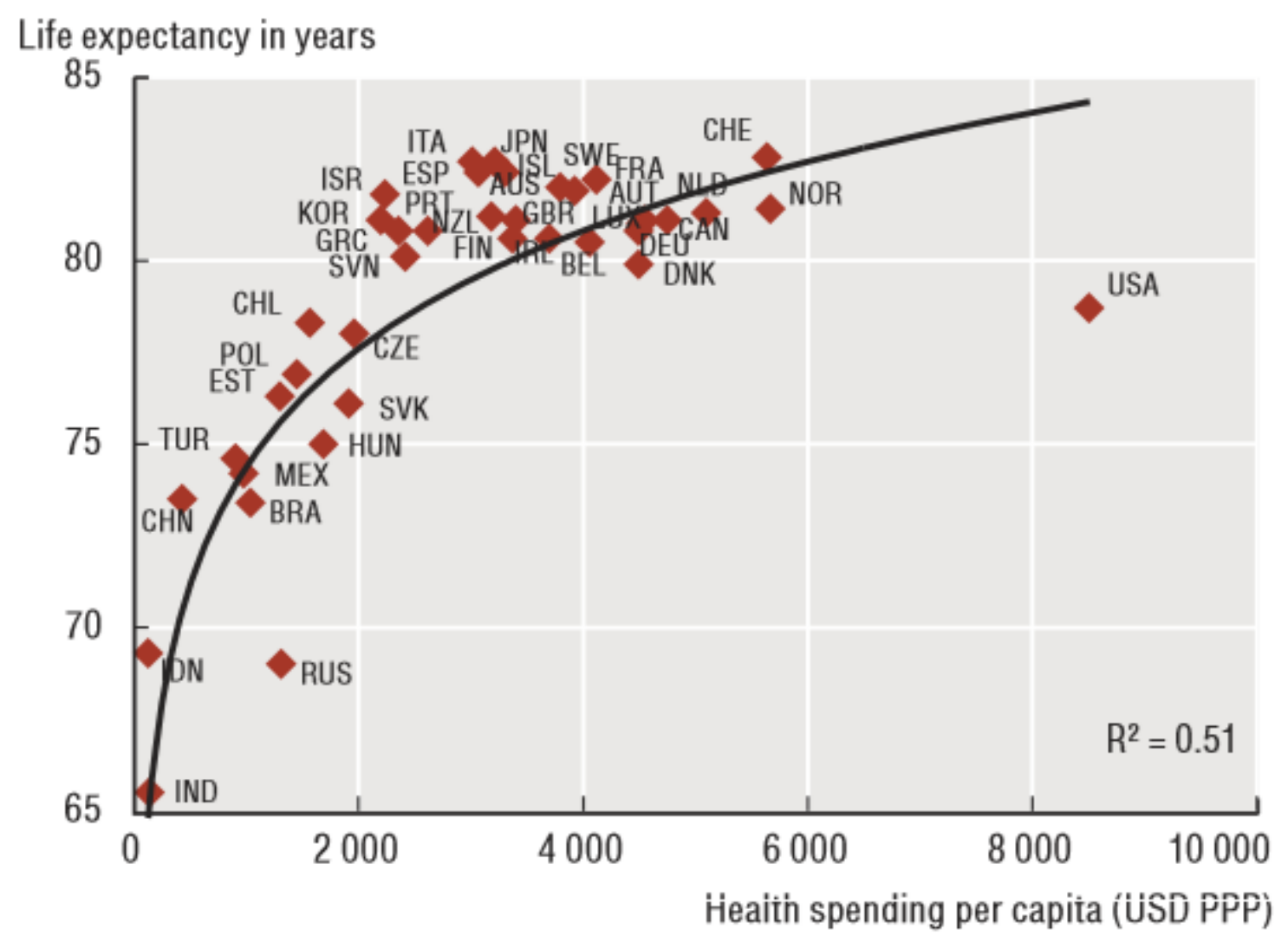

Figure 1. Life Expectancy and Health Spending Per Capita, (OECD, 2013)

U.S. demography has changed drastically since the Flexner Report. According to the U.S. Census Report (2002), while the general population more than tripled, the population aged 65 or older increased tenfold. Racial diversity has increased tremendously over the last 100 years as well. Moreover, the leading causes of death has shifted from infectious to chronic diseases (Guyer, Freedman, Strobino, \& Sondik, 2000). 
The issues within the current state of U.S. health care that merit improvement are multifaceted (Wong \& Holmboe, 2016). Political and economic forces, a dominant medical establishment and private insurance industry, and a wide-spread medical liability (Blank, 2012), health-care quality, structure and process (Jonas, Goldsteen, \& Goldsteen, 2007), health disparities (Williams, 2011), and overtreatment and denial care (Brownlee, 2007), revealing a complex web of problems (Jonas, Goldsteen, \& Goldsteen, 2007; Williams 2011). Concerted efforts at various levels and entities are necessary.

As stated in Chapter 1, education is a piece of the puzzle that could potentially make a change in the delivery of health care by preparing future physicians (Davis et al., 1999; Woollard \& Boelen, 2012) and changes are proposed and promoted by various entities.

\section{Rogers' Diffusion of Innovation Model}

“Change is neither natural nor normal” (Evans, 1996, p. 25). Despite obvious benefits, there are multiple factors preventing people from adopting new and innovative ideas. Yet, there are those whom Rogers (2003) defines as innovators and early adopters. Innovators, according to Rogers, are individuals who can cope with a high level of uncertainty, and early adopters serve as role models for other members and contribute to lessen uncertainties. Faculty members who are innovators and early adopters are the focus of this study. As explained in Chapter 1, for the purpose of this study, these two types of adopters are collapsed and considered as early adopters.

To explain the inner workings of how innovation is adopted and diffused by early adopters, Rogers (2003) defined five variables that determine the rate of adoption: 
perceived attributes of innovations, type of innovation-decision, communication

channels, nature of the social system, and extent of change agents' promotional efforts (see Figure 2).

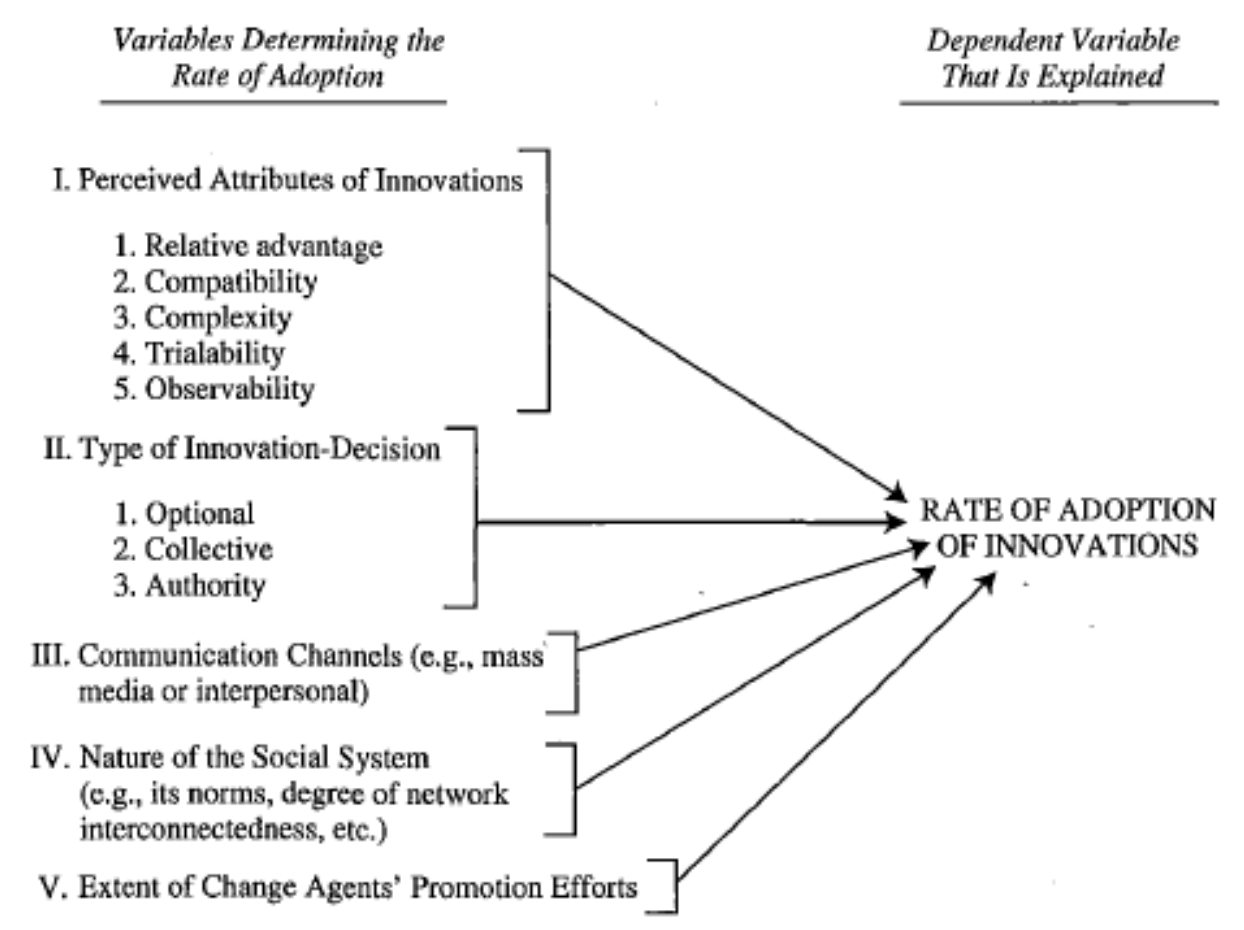

Figure 2. Variables Determining the Rate of Adoption of Innovations (Rogers, 2003)

In this study, perceived attributes of innovations will be used to frame and analyze intrinsic factors that affect faculty attitudes and behaviors. The remaining four variables - type of innovation-decision, communication channels, nature of the social system, and extent of change agents' promotional efforts - will be used as frameworks to pose questions and analyze extrinsic factors that impact faculty attitudes and behaviors in relation to curricular revisions. 


\section{Intrinsic Factors: Perceived Attributes of Innovations}

Rogers (2003) lists five perceived attributes of innovations: relative advantage, compatibility, complexity, trialability, and observability. In the following section, each attribute will be examined in the context of curricular revision.

\section{Relative Advantage}

Relative advantage is "the degree an individual perceives the innovation as advantageous" (Rogers, 2003, p. 15). In curricular revision, faculty perception of newly presented curricula and pedagogical approaches as improvements affects the rate of adoption. Faculty members who believe that learner-centered, active learning pedagogical approaches produce better learning outcomes would be more likely to adopt changes. In contrast, it is less likely that they will adopt change if unconvinced that such changes produce better learning outcomes than traditional lecture-based teaching (Yarnall, Toyama, Gong, Ayers, \& Ostrander, 2007).

In other words, faculty members must first perceive (or believe) that an innovation like curriculum revision will advantage themselves, their students, the program, the organization, and the profession. As such, the current state of medical education reform and pedagogical change are next described within the framework of relative advantage.

Medical education reform. Medical education has seen changes such as the introduction of diverse teaching methodologies. Examples include problem-based learning (Barrows, 2006; Kilroy, 2004), team-based learning (Michaelsen \& Sweet, 2011; Thompson et al., 2007), and simulation-based education (Issenberg, McGaghie, Petrusa, 
Gordon, \& Scalese, 2005; Okuda et al., 2009). However, the basic structure of medical education in the United States has largely remained unaltered (Gishen, Ovadia, Arzillo, Avashia, \& Thaller, 2014). Many medical schools maintained the traditional two-plustwo educational model that was introduced over a century ago (Hodges, 2010).

To address this, in 2010, the Carnegie Foundation for the Advancement of Teaching issued a report, Educating Physicians: A Call for Reform of Medical School and Residency (Cooke, Irby, \& O’Brian, 2010). Representatives visited medical schools and observed the paradigm that was put in place over 100 years ago. The report noted consistencies of quality of education among medical schools. However, they pointed out areas that needed changes, such as practice of medicine, expansion of medical and scientific knowledge and domains, creation of the graduate medical education (residency program), and deeper understanding of the nature of learning, and called for new curriculum, pedagogical and assessment approaches. They observed inflexibility of structure, teacher-centric education, heavy focus on in-patient training, poor integration of foundational knowledge and clinical science, insufficient coverage of the science of health-care delivery and population health. Similarly, Maeshiro et al. (2010) noted changes in public health in North America over the past century and urged the medical education community to take a new approach to educating tomorrow's physicians.

In consideration of these imperatives, Cooke, Irby, and O'Brian (2010) recommended four major goals: standardization of learning outcomes and individualization of the learning process, integration of formal knowledge and clinical experience, development of habits of inquiry and innovation, and focus on professional 
identity formation. The report served as catalyst for change among medical education community. The question at hand is whether the medical education community, including administrators and faculty members, perceive these innovative ideas to be better than those that proceeded. Rogers (2003) suggests that if faculty members perceive beneficial outcomes of a new idea (e.g. integration of formal knowledge and clinical experience) the rate of adoption increases.

Pedagogical change. One of the ways to achieve the change in medical education described by Cooke, Irby, and O'Brian (2010) is to conduct curricular revisions, specifically to pedagogical methods. As noted in Chapter 1, many medical schools are attempting to change pedagogical approaches from transmission of knowledge to one that is learner-centered.

With the development and understanding of learning theories, educational institutions are actively exploring various types of instructional and assessment methodologies. "One teaching and learning approach fits all— is not working for a growing number of student populations" (Brown, 2003, p. 49). Ludmerer (2004) also pointed out that development of critical reasoning, the ability to acquire, generalize, and evaluate information, requires a learner-centered curriculum. He concluded that excessive lectures and reliance on rote memory do not promote the desired learning outcomes. Blumberg (2012) elaborates on this point by saying that teacher-centered approaches put "too much emphasis on teaching at the expense of learning" and that unintended consequences include "graduates who are not prepared to solve real-world problems and lack the skills and motivation to continue to learn beyond their formal education" (p. 38). 
A learner-centered approach bases its foundation on constructivist and cognitive science theories. Ultimately, to foster life-long learning, students and faculty must shift from the traditional view of schooling where faculty and schools are responsible for students' learning to the learner-centered paradigm where students must take responsibility for their learning (Blumberg, 2012).

Cognitive science theory. Learning, according to Resnick (1989), is a process of knowledge construction that is knowledge dependent and highly situational. Mayer (1998) identified three stages of the learning process: selecting, organizing, and integrating. The first stage, selecting, is where learners go through cognitive processes of selecting relevant information and adding it to working memory. During the organizing stage, learners build internal associations among the selected information. In the final stage, integrating, learners connect the organized information to previously attained, existing information in their working memory.

With the advancement of medical science, the volume and depth of the basic scientific knowledge medical students are required to learn have exponentially increased over the last century (Scott, 2000). Tension exists between attempting to cover vast, basic scientific content and being selective about that which is fundamental to the practice of medicine. However, the capacity of that which can be stored in working memory has been proposed, by Miller, to be limited (Gilchrist, Cowan \& Naveh-Benjamin, 2009), and from a neuroscience point of view, trying to cram information simply does not work. In order for information to be processed into long-term memory, information must make sense and be relevant to learners. 
Clearly, the attainment of factual knowledge is essential before learners can analyze or synthesize. Indeed, Fink's (2003) taxonomy for significant learning begins with fundamental knowledge (i.e. understanding and remembering information and ideas), followed by application, integration, human dimension, caring, and learning how to learn. Background knowledge is necessary for reading comprehension and critical thinking. Similarly, Souza (2007) describes knowledge attrition and its importance in learning within a cognitive science framework using neuro-scientific evidence. He explains that the brain receives various sensory information from the environment that then gets stored temporarily in short-term memory (i.e. immediate and working memories) before the information is transferred and stored in long-term memory. The importance of sensory information from environment is determined consciously and unconsciously by an individual's prior experiences. The brain's main function is to create shortcut and deflect the brain from paying attention to unnecessary information. If knowledge attainment is fundamental to learning, faculty must create ways in which students learn materials.

To address students' concerns regarding the need to memorize and regurgitate basic scientific content, many medical schools are integrating active learning methods such as team-based learning, which is a form of collaborative learning that engages learners in purposeful activities (Anderson, 2010; Nagaswami et al., 2011.; Oakley et al., 2004).

Constructivist theory. Constructivism is based on the theory that the construction of knowledge happens at both individual and social (i.e. collaborative) levels. Learning 
takes place within a social context, and it interacts with our prior knowledge and experience (Perkins, 1999). Cleaver and Ballantyne (2014) summarized constructivism as the idea that "individuality, diversity and difference are acknowledged, and we assume that each individual constructs personal meaning" (p. 229). Bruner (1996) stated that instruction can be effective when instructors create engaging and stimulating experience allowing learners to construct knowledge in a way that gives personal meaning; this acknowledges that students come with prior knowledge and views that would act as a filter.

According to constructivist theory, students learn by actively participating in the learning process. Team-based learning is one of the active learning methods that Fink (2003) and many others have discussed. Oakley et al. (2004) point to numerous benefits of incorporating small-group learning, such as retention, achievement of higher grade, and the improvement of communication skills. One U.S. medical school conducted a comparison of traditional lecture-based teaching and team-based learning and found that team-based learning achieved higher scores on the National Board of Medical Examiners test (Nagaswami et al., 2011). Team-based learning acted as motivator for students to be self-directed learners (Bergmann \& Sams, 2008).

Similar findings were reported by the study conducted by Haidet, O'Malley, and Richards (2002). They conducted surveys on the effect of team-based learning at the Baylor College of Medicine. Traditionally, noontime conferences are held using a lecture format; however, with the rise of curricular reforms among many medical schools, focus on active learning and learner-centered pedagogy was introduced. Authors gave resident 
learners pre- and post-surveys on their attitudes toward the utility of sensitivity/specificity and positive/negative predictive value. Qualitative observations were also conducted by the authors, a teacher and an independent observer. Both the surveys and qualitative observations revealed that learners received team-based learning methods positively and were highly engaged.

Health-care professional programs beyond medical education are employing this active learning method. For instance, Huitt, Killins, Brooks, and Williams (2015) found team-based learning to be effective in an anatomy course for physical therapy students. They found that students had positive attitudes toward working with peers and higher academic performance compared to students who were in traditional courses.

\section{Compatibility}

Compatibility, a second perceived attribute of innovation, is defined as the degree to which an individual perceives values and belief of the innovation as consistent with existing ones (Rogers, 2003). In this section, the historical development and current state of medical education reform are described to illustrate shifts in values in medical education during the last century. Understanding principles and values fundamental to the formation of medical education is critical when exploring faculty members' perspectives in terms of Rogers' compatibility.

Historical formation of medical education in the United States. The Flexner Report of 1910 has been the single most influential event in the formation of the current state of medical education. In 1908, the AMA appointed the Carnegie Foundation for the Advancement of Teaching to conduct a study of U.S. medical schools. Many medical 
schools created their curriculum based on a two-plus-two model - two years of basic science curriculum followed by two years of clinical training (Cooke, Irby, Sullivan, \& Ludmerer, 2006).

In the late 19th century, U.S. health care took a major turn in terms of how medicine was delivered and what medicine was deemed to be good and worthy. The birth of allopathic medicine created competition and conflicts among medical fields. Allopathy relied heavily on scientific evidence; emphasis was placed on acquiring basic scientific knowledge. Traditional medical systems such as homeopathy and Thomsonian medicine were deemed inferior by allopathic doctors. Allopathic physicians organized the American Medical Association (AMA) in 1847 (Horowitz, 2013). According to Schmidt (2009), “AMA was set up in 1847 as a means of opposing competition from homeopathy" (p. 84). AMA flexed its muscles to ensure that its favored medicine, allopathy, prevailed over Thomsonianism and homeopathy. In part to spread their vision and to promote the restructuring of medical education, the AMA created the Council on Medical Education (CME) in 1904. The CME sought help from the Carnegie Foundation for the Advancement of Teaching in order to achieve nationwide implementation of standardized admission and medical curriculum,. Abraham Flexner, schoolmaster and educational theorist, was chosen to lead this initiative (Beck, 2004). The relevance of basic scientific knowledge was reinforced by the recommendations of his 1910 report (Goldstein, Lunn, \& Peng, 2015).

AMA's 20th century campaign to standardize licensing examinations led to the creation of the National Board of Medical Examiners (NBME) in 1915. Although states 
resisted adopting national, standardized examinations, gradually, through journal and national meetings, schools started to convert their requirements from state-level to national examinations. Publicly, it was presented as if the introduction and implementation of standardized examinations was to ensure the protection of citizens; however, politically, it was a way for an emerging group of allopathic doctors to gain control over the entire U.S. health-care system. (Horowitz, 2013). In 1992, the first iteration of licensing examination, the United States Medical Licensing Examination (USMLE), was administered and marked the beginning of the current state of standardized licensing examinations, replacing all previous pathways to attaining a license (Dillon, Boulet, Howkins, \& Swanson, 2004).

Compatibility of values. Understanding the historical context of medical education formulation is significant to this study as Rogers' (2003) compatibility component of innovation theory looks at "the degree to which an innovation is perceived as consistent with the existing values, past experiences, and needs of potential adopters" (p. 240). Values created a century ago are deeply instilled among the medical education community. In curriculum transformation, for example, integration of clinical science into basic science may be perceived as "science light" or as taking the time away from basic scientific content. Flexner created the foundation of the allopathic medical education in which basic scientific knowledge was imparted by faculty to learners. The perceived incompatibility of values and beliefs with the resulting allopathic system can either block or slow down adaptation of innovation (Rogers, 2003). 
Compatibility with past experiences in the role of teacher. Currently, medical education is founded on Flexner's Report, which placed an emphasis on basic science knowledge; two years of solid basic science curriculum followed by two years of clinical science has been widely accepted and embraced for the past century. Within the basic science curriculum phase, didactic methods have been used as the main teaching methodology by faculty, and the role of faculty was to impart basic scientific knowledge. In contrast, in a learner-centered approach, faculty "promotes learning by facilitating the acquisition of knowledge" (Weimer, 2002, p. 28).

The pedagogical changes discussed above do not necessarily come easily for faculty. Faculty are used to teach (i.e. transmitting intellectual property) to learners. The shift to learner-centered education requires faculty and students to recreate each other's role. "Teachers need to fully understand the complexities involved in their new roles as facilitators of knowledge building rather than transmitters of knowledge" (Dole, Bloom, \& Kowalske, 2016). While effective facilitation still requires teachers to have knowledge and expertise in a particular content area, the paradigm shift from "a teller of knowledge to a facilitator of learning” (Doyle, 2011, p. 53) may bring dissonance among faculty. The compatibility of the new idea with their past experiences influences individual's decision to adopt or refuse new pedagogy. As such, faculty with beliefs and past experiences of their roles as an expert transmitter of knowledge may find their new roles as facilitators incompatible. In contrast, faculty who value and have had learner-centered education based on constructivist and cognitive science learning theories may find new curriculum compatible; hence, they are more likely to adopt curricula change. 


\section{Complexity}

Complexity is the "degree to which an innovation is perceived as difficult to understand and use.... New ideas that are simpler to understand are adopted more rapidly than innovations that require the adopter to develop new skills and understandings" (Roger, 2003, p. 16). The perception that implementing active learning methods is too complex and difficult can impede the adoption of changes (Brownell \& Tanner, 2012). As shown in the previous section, numerous studies conclude that there are benefits of active learning methodology. However, these arguments are not without dissention.

Critiques of constructivist theory argue that active learning methodology such as team-based learning is time-consuming, expensive, and difficult to develop. Converting an hour-long PowerPoint lecture into an active learning method takes time and skills (Malone \& Spieth, 2012). The existence of such necessary efforts slows down the adoption rates for faculty members who perceive them as overly complex.

\section{Trialability}

Rogers (2003) asserts that trialability, the fourth perceived attribute of innovation, is "the degree to which an innovation may be experimented with on a limited basis" ( $\mathrm{p}$. 16). The perceived possibility to trial new active learning methods on a limited basis is critical in gaining a greater understanding of the methods and potential benefits (Penjor \& Zander, 2016). Warren (2006) also argues that simple active learning techniques can increase the adoption rates of new materials by faculty.

Trialability could also ease the perception of complexity. There are multiple active leaning methods, requiring varied levels of technical expertise and modification. A 
simple example, such as pause procedure, requires instructors to pause periodically throughout lectures to give learners dedicated time to sort and clarify materials with a partner in a classroom (Prince, 2004). It requires little preparation compared to other active learning methods such as team-based learning. Other simple techniques involve providing learners with an instant feedback card (Lawrence \& Shinham, 2015) or using the think-pair-share method in which learners are actively involved in their own and peers' learnings (Kagan, 1994). These simple techniques does not take much preparation time, but requires only minimal modification to existing teaching methods. Trialability allows faculty to test the waters and to experiment.

\section{Observability}

The fifth and last perceived attribute, observability, "[the] degree to which the results of an innovation are visible to others" (Rogers, 2003, p. 258), affects the adoption of innovation and rate of adaptation; observability of an innovation increases the rate of adaptation. Faculty perception of the adaptation of curricula change is affected by whether or not new ideas, (e.g. active learning methodologies and learner-centered pedagogical approaches) are easily observed and communicated. For instance, observing engaged learners in a classroom can have a positive effect on an active learning method. But some faculty may need to observe the effect of new methods on learning outcomes, which may be less visible and not readily observable. In such a case, the rate of adoption of a new pedagogical approach may be negatively affected.

The five perceived attributes of innovation presented-relative advantage, compatibility, complexity, trialability, and observability - concern intrinsic factors that 
contribute to the likelihood that faculty will become early adopters; this exploration offers insights for understanding the factors that affect the attitudes and behaviors leading faculty to engage in curricular revisions. However, these attributes do not fully explain how faculty become motivated. In the following section, in order to augment Rogers' (2003) perceived attributes of innovation, motivation theory will be examined as another intrinsic factor.

\section{Intrinsic Factor: Motivation Theory}

Curriculum change may require the complete overhaul of delivery methods and instructional content. Traditionally, educational institutions assumed that their faculty are self-regulated and self-motivated, but clearly, not all faculty members are intrinsically motivated (McLaren \& Kenny, 2015). In the following section, motivation theory is used to further explain how intrinsic factors motivate early adopters.

Pedagogical change involves "leaving comfortable roles behind and exploring new ways of using content and interacting with students" (Bender \& Weimer, 2005, p. 4) and learning new methodologies. If faculty are uncertain about curricular changes, they may become motivated to seek knowledge and information on how students learn, and why and how learner-centered, active learning promotes positive outcomes (Stage, Muller, Kinzie \& Simmons, 1998). So, what motivates faculty to be early adopters? Merriam and Beirema (2014) defined motivation as the drive and energy a person puts into accomplishing something he or she wants to do. According to Petri (1996), it is "the concept we use when we describe the forces acting on or within an organism to initiate and direct behavior" (p. 3). Intrinsic motivation to learn is one of the six adult learning 
principles listed by Knowles, Holton, and Swanson (2015). Intrinsic motivation, according to Ryan and Deci (2000), "is defined as the doing of an activity for its inherent satisfactions rather than for some separable consequence" (p. 56).

However, Misch (2002) rejected the notion of intrinsic motivation as simplistic, misleading, and counter-productive to understanding motivational factors. Furthermore, according to andragogy, adults are internally motivated, but in order to prepare for some future application, there are instances where learning is mandated (Merriam \& Bierema, 2014). Expectancy-value theory below explains the complexity of how faculty may or may not become motivated.

Expectancy-value theory. This theory emphasizes both value of the goal and the expectancy of successfully obtaining the goal. Tolman (1932) defined three properties of behavior: persistency, consistency of pattern, and selectivity. In this sense, behaviors are purposive. Expectancy is established when one learns that a certain behavior leads to a particular goal (Petri, 1996). Even if a goal is of a high value, if one estimates that obtaining the goal is highly unlikely, it may not generate much behavior. In curriculum revision, especially in learning a new pedagogical approach, if faculty members believe that the value of a new instructional methodology is highly attainable, they would be more likely to be motivated and to put effort into achieving the goal. On the contrary, if faculty do not believe the improved learning outcome is attainable, even they understand its value, they may not be motivated to change their pedagogical practice.

As argued by Misch (2002) and demonstrated by expectancy-value theory, the field of study of motivation is complex, multi-faceted, and often produces contradictory 
ideas, but its importance cannot be denied. In this study, along with Rogers' five perceived attributes of innovation, faculty motivation to seek out, learn, adopt, and implement curricular changes will be examined to understand what drives early adopters. Internal factors alone, however, cannot fully explain early adopters' attitudes and behaviors. They are also shaped by extrinsic factors, which will be examined in the following section.

\section{Extrinsic Factors}

External or extrinsic factors that affect the rate of adoption include the type of innovation-decision, communication channels, nature of the social system, and extent of change agents' promotional efforts (Rogers, 2003). In this section, each variable will be used to frame and examine extrinsic factors that affect intrinsic faculty attitudes and behaviors toward curricular changes.

\section{Type of Innovation-Decision}

The external factor, type of innovation-decision, may be characterized as optional, collective, or authority. An optional innovation-decision allows each individual to take almost complete responsibility for making an adoptive decision, whereas collective innovation-decision seeks consensus among the members of a system. These types of innovation-decision usually take time, slowing down the rate of adoption. In contrast, an authority innovation-decision may produce the fastest rate of adoption since an individual has no say in the decision to adopt the innovation. Rogers (2003) cautions that although the rate of adoption may be faster, the "authority decisions may be circumvented by members of a system during their implementation" (p. 29). In collective and authority 
decisions, the social system is intimately involved in decision-making. In understanding the attitudes and behaviors of the faculty who become early adopters of the curriculum revision, it is essential to analyze the type of decision as a layer of variables that affect the rate of adoption.

Sense of control, as described by Seligman (1976), could be completely diminished depending on the type of innovation-decisions. External factors such as control are constantly relevant to the rate of adoption. Environmental factors must also be considered. Heider (1958) identified two factors, internal and external, as attributions that people use to view the causes of important events in their lives. The internal factor, according to Heider, lives within the individual and includes needs, wishes, emotions, abilities, intentions, and effort. The external factor is environmental, which is out of individual's control. Similarly, Dancey and Henderson (2010) describe the external factors as situational characteristics of an instructor's environment. Faculty may have a desire to implement an active learning methodology, but environmental factors, such as classroom setting, may impede actualization. Seligman's (1976) study found that subjects that were not given control over their environment were very slow to learn, and often, failed to learn new response. One's sense of control plays a crucial role in motivation, hence affecting the rate of adoption.

\section{Communication Channels}

Roger's (2003) second extrinsic variable is that of communication channels, the means by which information and messages get from one unit or individual to another. Communication channels are essential because 
most individuals do not evaluate an innovation on the basis of scientific studies of its consequences... most people depend mainly upon a subjective evaluation of an innovation that is conveyed to them from other individuals like themselves who have already adopted the innovation (Rogers, 2003, p. 18-19).

A high level of communication channels can be expected to have a positive effect on the rate of adoption. In the case of curricular revisions, if benefits and processes of adopting a learner-centered active learning methodology are communicated through the channel described above, it could influence faculty attitudes and behaviors.

Communication channels are partially dependent upon a social system and its structure. In the next section, Rogers' fourth variable, the nature of the social system will be examined.

Khalil and Kibble (2014) surveyed faculty members who were involved in the implementation of new curriculum. The faculty members noted a lack of shared understanding in the transition from the design phase to implementation. Spark (2004) states that concrete, tangible, clear, and compelling shared vision must be created to drive a change. Similarly, Manning (2013) uses quantum paradigm to describe an organization's interconnectedness in which the communication network is essential for organizations to thrive.

Communication channels allow new ideas to flow easily among members of organizations and are positively correlated with adaptation of new ideas (Rogers, 2003). Wheatley (2006) discusses control: Historically, and still in many institutions, leaders were expected to control and manage employees and regulate every aspect of their work, 
including job assignments, procedures, time allocation, and communication. This is what Wheatley calls a road to suicide. The notion of control disregards the existence of multiple realities. Brafman and Beckstrom (2006) introduced idea of starfish model - a decentralized organization which emphasizes horizontal communication channels. In this model, networks and interconnectedness allow open communication for the sharing of knowledge and ideas. The starfish model is critical in creating a comprehensive and holistic curriculum as faculty members from various departments must work collaboratively and cooperatively to drive curricular changes.

Hanna (2003) compares the traditional academic culture to that which is currently emerging. He emphasizes the significance of creating informal, horizontal, and both internal and external communication that allows for alliances and partnership within and outside of the organization. Rogers (2003) shares this perspective.

Most individuals do not evaluate an innovation solely or perhaps at all on the basis of its performance as judged by scientific research. Rather, they decide whether or not to adopt on the basis of the subjective evaluations of the innovations conveyed to them by others like themselves (peers). (p. 247)

What Rogers suggests is that, although numerous empirical and scientific studies' results point to benefits of learner-centered, active learning pedagogy, one's peers' subjective evaluations weigh more.

Communication channels also affect observability. Innovative ideas which are easily observed or communicated within a social system have higher rates of adaptation (Rogers, 2003). 


\section{Nature of the Social System}

The third variable that determines the rate of adoption is the nature of the social system. In this section, elements of social systems, or more specifically, the organizational structure and norms of the system are examined.

A social system is "a set of interrelated units that are engaged in joint problemsolving to accomplish a common goal" (Rogers, 2003, p. 23). Social structure and social norms either inhibit or accelerate the rate of adoption. An organization, at the institutionlevel, must have a structure that allows faculty to utilize time and resources flexibly to experiment with new teaching methodologies. As aforementioned, today's faculty are taxed with ever increasing duties with shrinking resources. If implementation of curricular change allows for protected full-time equivalent or other benefits including monetary assistance, it may affect the rate of adoption.

Organizational structure is not the only contributing factor. Norms tell “individuals what behavior they are expected to perform” (Rogers, 2003, p. 26). Norms of medical education as an entity and norms of individual institutions have impacts on the rate of adoption. Medical education norms have changed tremendously over the last century. Norms of individual institutions or units, for example, how teaching and roles of scientists are defined within a single institution, can either hinder or facilitate curricular changes. In other words, the rate of adoption would be influenced if teaching is perceived as equally or more important than research or clinical responsibility and being recognized as early adopters contribute to attaining status among departments, institutions, and professional communities. 
Organizational Structure. In medical education, each school is comprised of discipline-specific departments (e.g. physiology and pharmacology, cell biology, psychiatry, internal medicine, etc.). Historically, medical education courses were constructed according to departmental discipline (Balcioglu, Bilge, \& Unluoglu, 2015) resulting in, for example, anatomy courses, physiology courses, cell biology courses, etc. Each department had intellectual and academic freedom to create and organize course content and teaching and assessment methodologies. However, with curriculum transformation, many medical schools are employing an integrated approach to education, namely, organ-system-based curriculum. In this curriculum, a course is organized by an organ and all foundational, clinical, and behavioral science knowledge related to the organ is presented in an integrated manner. In this model, there is no clear ownership, so to speak, of a course by a specific department. The departments that used to enjoy autonomy and monopoly may lose dominion and independence as well as the associated educational funding, affecting department's bottom line. Depending on the organizational structure and funding stream, economic factors could therefore promote or hinder from faculty to adopt changes.

Genthon and Joseclyn (1989) looked at curriculum revision from a faculty standpoint. They found the challenge to be in consensus building among faculty members from multiple disciplines concerning curriculum reform (e.g. course content and the sequence and purpose of education). Feelings of negation and a sense of loss and uncertainty may be shared not only by faculty members, but also by department chairs and administrators as a whole. Maslow's (1943) hierarchy of needs has five stages: 
physiological, safety, belongingness, esteem and self-actualization. One could argue that faculty members and even whole departments may share a sense of loss at the basic level of physiological needs.

Norms. Rogers (2003) asserts that norms "serve as a guide or standard for the behavior of members of a social system" (p. 26) that affect the rate of adoption. Kilmann, Saxton, and Serpa (1986) also stress the impact of organizational culture on individual behavior. In this section, the culture and norms belonging to the professional identify of a scientist in medical education will be examined.

According to Brownell and Tanner (2012), teaching is not considered as important as conducting research in the scientific disciplines. "Faculty members who want to be perceived as successful and 'real' scientists may have purposely avoided integrating teaching into their professional identities, because they feel it could undermine their scientific status with their colleagues, their departments, and their institutions" (Brownell \& Tanner, 2012, p. 342). If this norm exists in a medical school as an organization or at the departmental-level, it may affect faculty from taking the time to learn new pedagogical approaches and implement them. In this sense, investigating the norms of organization perceived by faculty members gives additional insight to explain factors that affect the attitudes and behaviors of early adopters.

\section{Extent of Change Agents' Promotion Efforts}

Rogers' (2003) fifth variable affecting the rate of adoption is the change agents' promotion efforts. A change agent tries to influence and steer an individual or unit toward adopting new ideas. The roles of change agents range from developing needs for change, 
establishing rapport with individuals or units and motivating them, diagnosing problems, and stabilizing changed behaviors (Rogers, 2003, p. 371). In this section, national-level change agents' promotion efforts for curricular changes in medical education will be described, followed by a description of institutional-level efforts, specifically, faculty development efforts.

National-level promotion efforts. National-level professional associations, including AMA, AAMC, Liaison Committee of Medical Education (LCME) and Accreditation Council for Graduate Medical Education (ACGME), are all coming up with initiatives for changes. Organizational-level promotion efforts will be described in a later segment, but first, national-level, professional associations' initiatives to change medical education will be illustrated to demonstrate the inundation of external forces.

American Medical Association. AMA is a professional association, and as described in the previous section, has been playing a key role in U.S. health care since its inception. The association's mission is “to promote the art and science of medicine for the betterment of the public health" (AMA Mission \& Guiding Principles). Although they are experiencing a sharp decline in membership-AMA membership was around 15\% down in 2011 from 75\% in the early 1950s (Collier, 2011) — they still hold political influence at the national level.

The AMA's influence in medical education can be seen in various areas but notably in the grant opportunity announced in 2013,. In 2013, which was based on a strategic vision in three areas: improvement of nation's health outcomes and reduction of health care costs, alignment of education and training with the evolving health care 
system, and enhancement of professional satisfaction and practice sustainability (AMA, 2013). The grant aimed to alter medical education through innovative and bold changes. The interest among medical schools to modify their education was tremendous; more than $80 \%$ of medical schools submitted letters of intent, only 11 of which were awarded grants.

Accreditation Council for Graduate Medical Education. ACGME is the accreditation agency for all U.S. clinical residency and fellowship programs. Its mission is to "improve health care and population health by assessing and advancing the quality of resident physicians' education through accreditation" (ACGME Mission, Vision, and Values). In 1999, in the hope to improve the education of residents, the ACGME formulated and endorsed six domains of competencies (i.e. medical knowledge, patient care, practice-based learning and improvement, system-based practice, professionalism, and interpersonal and communication skills for all residency programs) (Leach, 2001; Nasca, Philbert, Brigham, \& Flynn, 2012; Swing, 2007). The establishment of these competencies were created "to help promote public confidence in medical education and to ensure the production of competent physicians" (Quillen, 2001, p. 652). ACGME's influence on medical schools is inevitable as all U.S. medical students must gain residency positions in order to become full-fledged physicians. Medical schools are, in essence, preparing students for their residency. To that end, the adaptation of a competency model made sense to the medical school community.

Association for American Medical Colleges. AAMC is a non-profit organization. According to their website, "the AAMC serves and leads the academic medicine 
community to improve the health of all" (AAMC Mission). They hold all 145 accredited

U.S. medical schools as their members. To lead the change among medical schools, AAMC created the Physician Competency Reference Set (Englander et al., 2013) which includes the ACGME's six competency domains, but added interprofessional collaboration and personal and professional development.

In 2015, AAMC published a draft set of 13 core entrustable professional activities (EPAs). Each core EPA is linked to competencies across multiple competency domains. EPAs for medical students were developed to help educators to identify the overall clinical performance outcome of students and professional development (Chen, van den Broek, \& ten Cate, 2015).

Liaison Committee of Medical Education. Another regulatory body that governs medical schools and education is LCME. It was established in 1942 and accredits U.S. and Canadian medical schools. The initial meeting was held conjointly by AMA and AAMC to address concerns regarding accelerated education programs (Kassebaum, 1992). According to LCME's website, “the Liaison Committee on Medical Education is recognized by the U.S. Department of Education as the reliable authority for the accreditation of medical education programs leading to the MD degree" (LCME, 2015). Standards set forth by LCME serve as driving agents and are adopted by medical schools in their educational missions. LCME conducted a major revision of standards in order to increase objectivity and reduce subjectivity in 2002 (Hunt, Migdal, Eaglen, Barzansky, \& Sabalis, 2012). In 2015, it introduced new standards. These standards have a great impact on curriculum reform at the school level. For instance, one of the competency domains, 
system-based practice, addresses issues of the system and delivery of health care. During the basic science curriculum phase, due to limited curricular time, adding topics such as social science and behavioral science is difficult, but accreditation standards can be used to legitimize these topics.

Various national organizations in medical communities are calling to take actions to improve the education of our future physicians. As evident in the proportion of medical schools that submitted letters of intent for the AMA's grant for curriculum transformation, the majority of medical schools are either intending to or are in the process of implementing new curriculum. In essence, at the national-level, the extent of change agents' promotional efforts is succeeding in creating imperatives for change.

However, despite the national movements and the current state of the health-care system, faculty buy-in remains the major challenge for administration (Tagg, 2012). In the following section, institution-level promotion efforts, specifically issues surrounding faculty development, will be explored.

Institution-level promotion efforts. At the institution-level, faculty development is an external factor essential in promoting academic excellence and innovation. Offering carefully planned, wide-ranging development opportunities can have a positive effect on the rate of adoption (Michael, 2007). In fact, Martell (2004) points to faculty development as a key to success in team-based learning or any active learning methodologies.

Historically, it was assumed that faculty are naturally good teachers (Wilkerson \& Irby, 1998). However, given the complexities of the instructional and assessment 
methodologies along with a diversified student body and competing demands on faculty members' time, it is now widely acknowledged that faculty development plays a critical role (Steinert et al., 2006). Curriculum overhaul requires faculty buy-in but also extensive and effective faculty development, which must accompany resources and time to allow faculty members to engage in new methods of active learning and multi-modal assessments (Holmboe et al., 2011); resources should be invested at an early stage of curriculum development (Farmer, 2004). Systematic and well-planned faculty development may help lessen perceived complexity. Faculty development can also address trialability. For instance, introducing a simple technique of active learning, such as the incorporation of clicker questions (Martyn, 2007) or in-class student teams (Yoder \& Hochevar, 2005), may reduce the perception of complexity and increase the probability of trialability.

In this study, faculty perception on national-level change initiatives and an institution's faculty development efforts will be investigated in an effort to gain understanding of how these variables affect faculty attitudes and behaviors in adopting curricular changes.

\section{Summary}

Curriculum transformation has major impacts on multiple areas of educational aspects. This chapter began with a discussion of the current state of U.S. health care, which provided background information that demonstrates why changes are needed in medical education. This was followed by an exploration of the issues related to curriculum transformation using Rogers' (2003) diffusion of innovation model and a 
consideration of intrinsic and extrinsic factors. Medical education is experiencing a tide of change. Faculty are an integral part of curriculum transformation; without faculty buyin and a shared vision, the implementation and operation of curriculum revision would be jeopardized. No matter how many administrations try to offset resistance, it may be inevitable. Rather than focusing on resistance, this study will place a focus on factors that contribute to faculty's adaptive attitudes and behaviors using Rogers' diffusion of innovation model.

Holistic review and analysis of curriculum revision require gaining understandings of the effect of curriculum transformation on faculty according to their own insights. Curriculum revision, in many instances, is spearheaded by administration without authentic incorporation of faculty perspectives.

One's construction of reality may not be shared amongst all parties involved. Understanding the subjectivity of reality is key to creating a common ground from which faculty, administration, and students can work. By shedding light on faculty views, administrators will be able to make more fully informed decisions about the outcomes of potential adjustments in curriculum transformation as a part of ongoing quality improvement. 


\section{CHAPTER 3: Research Methodology}

As described in chapters 1 and 2, the current state and delivery of U.S. health care is suboptimal compared to many other industrial nations. In response, national-level medical professional associations, such as AMA, AAMC, ACGME, and LCME, are driving changes to transform medical education. MD program education alone cannot change the entire health-care system; however, it can act as a catalyst of change by educating students in areas that were historically underrepresented in medical education. In addition to changing curricular content and structure, many medical schools are implementing various active learning methods to promote learner-centered education. Faculty involvement is crucial in implementing curriculum transformation. Understanding the best methods and approaches for faculty involvement in curricular revision is important to medical education, and ultimately, to the health of the population. Thus, this study examined faculty perspectives on and engagement with medical education curricular revisions.

\section{Research Questions}

The overall research question for this study asked what factors foster medical education faculty to revise their curriculum. Specifically, the study intended to answer following questions:

1. What extrinsic factors influence faculty to adopt curricular transformation, specifically learner-centered active learning pedagogy?

2. What intrinsic factors influence faculty to adopt curricular transformation, specifically learner-centered active learning pedagogy? 
3. What are some of the best practices of learner-centered active learning methods?

4. What do faculty suggest as organizational supporting factors for curricular transformation?

\section{Narrative Analysis Method}

The study was conducted at a northwest medical school that recently underwent a curriculum revision. Based on Rogers' (2003) innovation-decision process model, this narrative analysis study of faculty interviews intended to explore motivational factors, both intrinsic and extrinsic, that contributed to faculty early engagement in and adoption of curricular revisions.

Bryman (2008) defines qualitative research as a "research strategy that emphasizes words rather than quantification" (p. 366). As such, narrative analysis, a qualitative research method, was utilized in this study. "Narrative inquiry is stories lived and told" (Clandinin \& Connelly, 2000, p. 20). "Stories express a kind of knowledge that uniquely describes human experience in which actions and happenings contribute positively and negatively to attain goals and fulfilling purposes" (Polkinghorne, 1995, p. 8). Narratives give researchers windows and ways to understand participants' experiences (Robert \& Shenhav, 2014). Mitchell (1981) defines the narrative as a "means by which human beings represent and restructure the world" (p. 8). According to Bruner (1990), the narrative is the "organizing principle by which people organize their experience in, knowledge about, and transactions with the social world" (p. 35).

In this case, narrative analysis allows the researcher to hear participants' voices about their experiences, lenses, knowledge, beliefs, values, and situations. It allows the 
researcher to develop descriptions of insights of participants. In this sense, the aim of the inquiry is not to find factual matters or truth, rather, it focuses on the ways in which faculty use stories to present and represent themselves while recognizing that knowledge attained through narrative analysis is partial, situational, and provisional. Moreover, multiple truths, interpretations, perspectives, and meanings are fundamental to narrative analysis, in which subjects and researchers co-construct meanings. Although the representation of reality is partial, selective, and imperfect, the value of conducting narrative analysis lies in uncovering and learning about the perspective of others and how they create meanings.

\section{Interview Protocol}

Interview questions were drawn and designed to address the study's research questions. They were developed and organized using Rogers' (2003) diffusion of innovation model and motivation theory. Namely, perceived attributes of innovations (i.e. relative advantage, compatibility, complexity trialability, and observability), type of innovation-decision, communication channels, nature of the social system, and extent of change agents' promotional efforts are used as foundations to generate interview questions. Additionally, motivational theory was used to augment Rogers' diffusion of innovation model in order to explore and understand early adopters' attitudes and behaviors. See Appendix A for a description of interview question development and Appendix B for complete list of questions.

The use of semi-structured interviews allows researchers to probe ambiguous or inconsistent responses (Hutchinson \& Skodol-Wilson, 1992). "Each interview question 
should be clearly connected to the purpose of the research, and its placement within the protocol should reflect the researcher's deliberate progression toward a fully in-depth exploration of the phenomenon under study" (Galletta, 2013, p. 45).

First, a couple of background questions were asked to gain basic background information from each participant. To address the research question on best practices of learner-centered active learning methods, pedagogical questions were asked.

The development of questions to explore intrinsic factors was based on the five perceived attributes of innovation. (relative advantage, compatibility, complexity, trialability, and observability). For instance, to address Rogers' (2003) relative advantage, interview questions elicited faculty members' beliefs about and perceptions of the benefits of the learning methods they had incorporated and the reasons why they felt that such methods constituted improvements. Interview questions in relation to compatibility were developed to address the values and beliefs of faculty early adopters. For example, one interview question asked, "for the past century, medical education has based its foundation on Flexner's report, which placed importance on basic science curriculum. As many medical schools are going through curricula revisions, how do you see the role of basic science curriculum in medical education?" This question was intended to explore whether faculty members felt that the trend in curricular changes was compatible with their belief and values. Similar to these examples, interview questions to address the issues of complexity, trialability, and observability were formulated to examine the participants' perceptions for insight on intrinsic factors that have influenced early adopters. 
Extrinsic factors were likewise addressed through questions created from the framework of Rogers' (2003) variables. For instance, one interview question addressed the participants' knowledge about the national initiatives and movements calling for medical education curricular revisions. Understanding their knowledge of these movements and of learner-centered, active learning was essential in uncovering factors that contributed to their adoption of the change. Similarly, other interview questions were developed with consideration to the effect of the type of innovation-decision and other extrinsic variables, such as communication channels and the nature of the social system, in order to specifically address the external factors that affected the rate of adoption.

\section{Research Site}

When selecting a site, researchers must consider the following concerns: cost, timeline, geographical locale, and access (Glesne, 2016). This study was conducted at the researcher's workplace; therefore, the access issues about which Glesne cautions did not pose a problem.

The research site offered comprehensive health science education. The MD program was one of the programs housed in the School of Medicine, along with graduate studies and the undergraduate program. In 2015, according to the institution's fact book, the total MD student body was 556. A total of 2,785 faculty members were employed in 2015 at the institution, of which 2,023 were employed at the School of Medicine.

The School consisted of 7 basic science departments (i.e. behavioral neuroscience, biochemistry and molecular biology, biomedical engineering, cell, developmental and cancer biology, molecular and medical genetics, molecular 
microbiology and immunology, and physiology and pharmacology) and 19 clinical science departments, in addition to 22 centers and institutes.

The school rolled out a curriculum overhaul beginning with the entering class of 2014. The overhaul consisted of a realignment of the duration of two major curriculum phases: basic science curriculum and clinical science curriculum. This model lasted more than two decades, existing since 1992 when a major curriculum revision took place (Fields, Toffler, Elliott, \& Chappelle, 1998). In February 2012, the dean charged an associate dean to lead the redesign of the MD curriculum. The Steering Committee was formed to create an overall direction and the goals of the revision including an examination of the existing curricular elements, a needs assessment, identification of the educational characteristics necessary to produce 21 st century physicians, the alignment of competencies into curricular content, the development of curriculum that was a learnercentered, and determination of the overall structure of the curriculum.

In 2013, the school was selected as one of the 11 schools to receive grants from the American Medical Association to innovate its medical education. The grant provided each school one million dollars (over a 5-year period) to augment resources needed to achieve innovation.

\section{Population and Sample}

Purposive sampling of faculty allows the researcher to choose individuals to interview who have the information and perspectives critical to this study (Krathwohl, 2009). A set of semi-structured interviews, a tool appropriate to the exploration of values, beliefs, opinions, perceptions, and attitudes, were used (Richardson, Dohrenwend, \& 
Klein, 1965; Smith, 1975). The purpose was to examine participant views of the curriculum revision in order to identify any pattern of meaningful factors that facilitate engagement in the revision process.

The goal here was not to find the truth about faculty perspectives, because, as Guba and Lincoln (2005) state, "no method can deliver on ultimate truth" (p. 205). Each person holds different experiences, interpretations, and emotions. In this sense, all observations and evidence are fallible and only through triangulation of multiple fallible viewpoints, can objectivity be achieved within each arena and society. Still, the goal is to gather enough data to create a relatively accurate picture that illustrates the phenomenon in question.

In this study, the faculty members who were interviewed were selected from the basic science curriculum phase. In addition to decreasing the length of the curriculum phase as a whole, the curriculum transformation at this institution included the restructuring of courses from discipline-based to organ-based. In the previous curriculum, basic science courses were organized by disciplines such as cell structure, pharmacology, etc. which corresponded with basic science departments. This allowed each basic science department to oversee courses, including content, teacher selection, and teaching methodologies. However, the new curriculum broke the silos of compartmentalized courses, forcing departments to relinquish full control over courses. Only a few course directors from the former curriculum continued to have leadership roles in the new curriculum. 
To be eligible for this study, faculty members must have had taught in one or more of the nine former basic science courses in large-group settings. The 2012-2013 and 2013-2014 academic year teaching records were available to the researcher in an Excel format as well as in a database, Faculty Dossier, which was developed by in-house programmers. Faculty members must have also had taught during the initial year of curriculum transformation (i.e. in the 2014-2015 academic year, summer 2015, and the fall terms of the 2015-2016 academic year) in one of seven basic science courses in a large-group setting. Participants must have had faculty ranks, which were defined by the institution's faculty affairs. The database of faculty lists was available to the researcher in an Excel format. Faculty members who have taught in both curricula (former and new) were also be eligible to participate in this study. Successful early adopters were identified by block directors. Each basic science course had two block directors who manage all aspects of the courses. An additional source was the student survey, which took place in February 2016, asking each student to list the three best faculty teachers in the new curriculum.

\section{Sampling Method}

Cameron's (2001) suggests, "while in principle it might seem desirable to have as many examples as possible, in practice you have to draw the line somewhere" (p. 29). In this study, originally, ten faculty members who are identified as early adopters of the curriculum revision were going to be interviewed as Strauss and Corbin (1998) advise that at least ten interviews or observations with detailed coding are necessary for building a grounded theory (p. 281)" (Saldana, 2015, p. 90). These 10 faculty members were 
going to be randomly selected from 20 faculty members who are purposively selected using Patton's (2002) purposeful random sampling strategies. The purposive sampling approach allows researchers to sample participants who meet predetermined criteria (Bryman, 2006). According to Patton, "for many audiences, random sampling, even of small samples, will substantially increase the credibility of the results" (p. 179). However, Patton cautions that researchers must understand that purposeful random sampling is not a representative random sample. He states, "the purpose of a small random sample is credibility, not representativeness" (p. 180).

Each of the seven course directors were asked to identify early adopters - faculty who are engaged, committed and willing to create content and to facilitate students' academic success in the new curriculum. 59 faculty members were identified, of which 12 were identified by multiple course directors. A database with a list of faculty who were involved in teaching in old curriculum as well as new one in its inaugural year was referenced and 25 out of 47 were identified. Composition of the 25 faculty included two assistant professors, 11 associate professors and 12 professors; 7 were female and 18 were male.

Hence, out of 47, total 25 faculty members were deemed to fit the sampling criteria for this study. Using Microsoft Excel random selection tool, a list of 10 faculty members was generated and they received email invitations to participate in the study. Seven agreed to participate. Ultimately, it was decided to modify a sample size to seven instead of 10 which was the original proposed number. 
Out of three faculty members who declined the invitations to participate in the study, two gave their reasons and both were similar in nature: due to the student researcher's position in the central administration, they did not feel comfortable discussing the curriculum transformation.

\section{Participant Demographic}

Of seven faculty participants, three were associate professors; two female and one male. Four professor-rank faculty were all male. Years of teaching at the institution ranged from 9 to 44 years. Teaching involvement in the new curriculum ranged from 3 to 19 hours. The participants unanimously responded that they had not received a formal education on teaching. "I had a very little guidance on it" (Faculty 3). "Not personally" (Faculty 6). "Through TA, very rudimentary training. Basically learning while doing it. Faculty gave some guidance. When I knew I was going to take this job here, I realized I needed to educate myself" (Faculty 5). However, all responded that they learned by role modeling. Faculty 5 described his training on teaching as "very rudimentary training through TA." None of the faculty participants had an education degree; all them stated that they have attended seminars or workshops provided by the institution, their academic associations or other venues. Faculty 4 indicated that he continued to take online courses. The table below summarizes participants' background information: 
Table 1

Background Information of Participants

\begin{tabular}{|l|l|l|l|l|}
\hline Faculty & Gender & $\begin{array}{l}\text { Number of } \\
\text { years teaching }\end{array}$ & $\begin{array}{l}\text { Number of years } \\
\text { teaching at the } \\
\text { study institution }\end{array}$ & $\begin{array}{l}\text { Received any } \\
\text { formal trainings } \\
\text { in teaching }\end{array}$ \\
\hline Faculty 1 & M & 44 & 44 & No \\
\hline Faculty 2 & M & 11 & 10 & No \\
\hline Faculty 3 & F & 12 & 9 & No \\
\hline Faculty 4 & M & 25 & 24 & No \\
\hline Faculty 5 & M & 39 & 28 & No \\
\hline Faculty 6 & F & 13 & 10 & No \\
\hline Faculty 7 & M & 27 & 25 & No \\
\hline
\end{tabular}

\section{Data Collection Procedures}

First, the Human Subject Approval application was submitted. Upon approval, letters requesting participation in the study were emailed to twenty faculty members with a purpose of study. Consent forms were provided and obtained from each participant. Semi-structured interviews rather than focus groups were conducted "in order to encourage discussion of personal views" (Shaunessy-Dedrick, Suldo, Roth \& Fefer, 2015, p. 117) and to avoid the formulation of responses with assistance from other participants (Bailey, 1987). Semi-structured interviews allowed the researcher to probe for more information and to clarify answers as needed. Interviews were recorded using a voice recorder with permission from each interviewee. The use of a voice recorder provided a detailed account of the participation of the interviewees and the researcher. Interviews occurred at the interviewees' school. The date and time of the interviews were 
based on the interviewer's and interviewees' availability. The semi-structured interview took approximately 60 to 90 minutes. Notes were taken for observations that could not have been captured by voice recorder.

\section{Transcription}

Interviews were transcribed and verification of the transcription was conducted for accuracy. Riesman (1993) cautions that "different transcription conventions lead to and support different interpretations and ideological positions, and they ultimately create different worlds" (p. 13). The point Riesmann is making here is that the act of transcribing adds another layer of complexities, partiality, incompleteness, and selectivity. She uses photography to illustrate this point. Just like a photographer crops images reflect his or her aesthetic values and view, researchers in this stage are essentially creating meanings that fit their values. In this study, narratives attained from interviews were transcribed, and using the initial coding (Saldana, 2015), the researcher consciously highlighted pertinent points. Transcription was not as mechanical as it sounds; a word could have different meanings to different people. For instance, the usage of learner-centered or active learning in itself might have different connotation depends on experience, background, belief, and situation factors.

\section{Data Analysis}

This study was based on thematic analysis, as shown in Figure 3, which involves the identification of themes (Boyatzis, 1998; Creswell, 2012). Gallette (2013) states that "the analysis is ongoing, as you note thematic patterns emerging in the data" (p. 119). "In thematic analysis, the researcher focuses analytical techniques on searching through the 
data for themes and patterns" (Glesne, 2016, p. 187). Initial coding gives an opportunity "to reflect deeply on the contents and nuances" of data (Saldana, 2015, p. 85,), and will be used to generate themes.

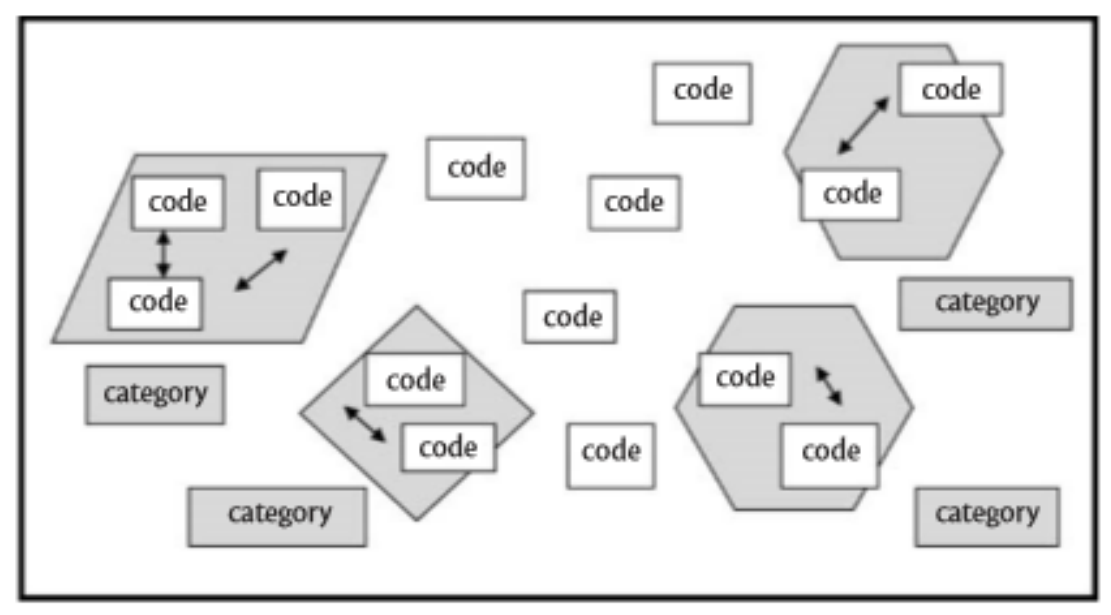

Figure 3. Thematic Codes and Categories (Galletta, 2013)

Qualitative coding allowed researchers to uncover relationships between various contexts; for instance, in this study, answers to each question (see Appendix A) were first coded separately; however, after initial coding, the interrelatedness of intrinsic and extrinsic motivations was analyzed to get an overall picture of faculty perspectives. The process of coding and categorization allowed the time and space to process, reflect, make meanings, create connections, and imagine the final write-up. To aid this process, Saldana (2015) suggests writing analytic memos as data gets coded in order to promote metathinking and to confront assumptions. This was achieved by revisiting the research purpose and questions, establishing connections with interviewees, reflecting on code schemes, writing and reflecting on emergent themes and their interrelatedness, considering the theoretical framework, and writing about any problems or ethical 
dilemma encountered in the process. For the purpose of this study, the following coding categories were used:

Table 2

Coding Categories

Intrinsic Motivation

IM

Relative Advantage

IM-RA

Compatibility

IM-CPB

Complexity

IM-CMP

Trialability

Observability

IM-TR

IM-OB

Extrinsic Motivation

EM

Type of Innovation

EM-TI

Optional

EM-TI-O

Collective

EM-TI-C

Authority

EM-TI-A

Communication Channels

EM-CC

Nature of the Social System

EM-NSS

Extent of Change Agent's Promotion Efforts

EM-CA

Best Practices

BP

\begin{tabular}{cl} 
Organizational Supporting Factors & OSF \\
\hline Negative & OSF-N \\
Positive & OSF-P
\end{tabular}

\section{The Role of the Researcher}

Researchers' perspectives, worldviews, and identities all influence one's approach to research and interpretation. Researchers, according to Hertz (1997) are

imposed at all stages of the research process - from the questions they ask to those they ignore, from who they study to who they ignore, from problem formulation to analysis, representation and writing — in order to produce less distorted accounts of the social worlds (p. viii). 


\section{Reflexivity}

Interview, in nature, is a process in which interviewees and interviewers co-create value. Researchers are embedded within the study and their own perspectives and views impact their interpretations (Creswell, 2003). In this paradigm, meaning-making occurs through human interaction, and interpretation is shaped by both participants and researchers as well as the act of analysis taking place throughout the process. As a researcher, it is crucial to accept the challenges of reflecting on the relevance of our stance, beliefs, and values in producing knowledge as "research is a product of the values of researchers and cannot be independent of them” (Mertens, 2010, p. 16). During narrative analysis, researchers must remain cognizant of subjectivity, complexities, and ambiguity of reality and examine the presence of their perspectives, biases, and interpretations at each stage. In each stage of this study-formulation of the purpose statement and research questions, selection of research methods, coding choices, the site, participants, and the creation of themes and conclusion, is exposed to subjectivity. For instance, the formulation of an interview question can have a major impact on setting the tone and direction of research. For instance, an interview question, "How do you see the role of teaching in a health science research university?" implicitly signified the divided roles of teachers and researchers, which could be suggestive to interviewees. Galletta (2013) suggests documenting such interference and to include it in the limitations of the research. 


\section{Positionality}

Along with reflexivity, positionality offers additional layers of lenses to research process. Positionality is determined "by where one stands in relation to 'the other"" (Merriam et al., 2001, p. 411). "Critically reflecting on positionality is an important aspect of the research process, but is also an aspect that helps us to respond to personal bias" (Gormally \& Coburn, 2014, p. 877). This study was conducted at a northwest medical school where the student researcher had been working for the past seven years as a part of the administration team in the Office of the Dean, initially as a curriculum manager of education and student affairs office, subsequently as a manager of curriculum \& student affairs. Merton's (1972) defined insiders as “the members of specified groups and collectivities or occupants of specified social statuses" (p. 21). Interviewing medical education faculty at the institution where the student researcher carried benefits such as access. However, Gormally and Coburn (2014) cautions for "the potential for 'insider complacency', where assumptions of knowledge and/or understanding of the setting may occur, rather than seeing or interpreting what was actually present or reported through a more critical lens" (p. 879). The student researcher also was intimately involved in curriculum transformation at the institution from the initial workgroup, as a member of curriculum development team, and the initial year of operation as a staff member of the Dean's Office. The positionality as a part of administration could potentially acted as hindrance for faculty to share their stories and perspectives if trust was not established between the interviewees and the student researcher. It was critical to acknowledge, carefully analyze and take into consideration of positionality using self-reflection. 


\section{Validity and Reliability}

Validity in research can take many forms. Definitions Guba and Lincoln (1994) provide range from conventional benchmarks of rigor to trustworthiness and authenticity. In narrative analysis, researchers are concerned with the trustworthiness of interpretations. It is not within the role of researchers to validate truth. Riessman (1993) explains four ways to approach validity in narrative analysis: persuasiveness, correspondence, coherence, and pragmatic use.

"Persuasiveness is greatest when theoretical claims are supported with evidence from informants' accounts and when alternative interpretations of the data are considered" (Riessman, 1993, p. 65). This does not guarantee validity as perceptions of findings are not constant or stable. Another way to increase validity is correspondence, which means to go back to consult with participants about interpretations and analysis. The third way to approach validity, according to Riessman (1993), is coherence means that the overall goal of narrator, what the narrator is trying to effect, and content all must share a sense of cohesiveness in order to show that the interpretation is more than ad hoc. Lastly, Riessman argues that researchers can provide information for readers to determine the trustworthiness of the study by providing "(a) describing how the interpretations were produced, (b) making visible what we did, (c) specifying how we accomplished successive transformation, and (d) making primary data available to other researchers". 


\section{Ethical Issues}

\section{Participation}

Glesne (2016) states that "if your questions identify issues of importance to interviewees, then interviewees will invariably both enjoy and find useful their roles as information providers" (p. 168). Krathwohl (2009) also states that the collaborative nature of the research study "gives [participants] increased feelings of self-worth" (p. 212).

Throughout this study, participants were given multiple opportunities to opt out. On the day of interview, participants were asked whether or not they would like to withdraw from the interviews. Informed consent was obtained prior to each interview (see Appendix C), and participants was informed that at any given time, if they would like to terminate interviews, they could do so without any penalties or guilt. In this study, since some participants knew the student researcher, they could have felt compelled to continue with interviews. The student researcher paid special attention to interviewees' facial expressions, gestures, and responses in an attempt to ensure that participants did not feel forced to complete the interviews.

\section{Confidentiality}

Confidentiality was maintained by using pseudonyms throughout and after the completion of the study. Krawthwohl (2009) argues that "confidentiality of data must be maintained so that individuals or institutions cannot be identified in ways that may be harmful or invite undesirable comparison" (p. 214). Pseudonyms were assigned to all participants including all faculty members who were invited. The data containing participant names and pseudonyms was kept in the student researcher's workplace cloud 
storage space to which only the researcher had access. If a department's name was mentioned during the interview, it was de-identified as well.

\section{Limitations}

As with the majority of research, the design and findings of the current research was subject to limitations. Samples size in this study was modified from ten to seven faculty participants. Although a set of minimum number of participants is not defined in the qualitative study as Patten (2002) suggests qualitative study seeks credibility rather than representativeness, and the goal of the current study was not to generalize findings but to gain deeper understanding on extrinsic and intrinsic motivation and perspectives particular to the faculty participants' situations and experiences, the student researcher could have gained different perspectives from those faculty who expressed that they did not feel conformable participating in the study. In addition to the number of participants, as some researchers suggest significance of representation of genders in research (Holdcroft, 2007), it should be noted that the majority of faculty participants were male; only two females participated in the current study.

Another potential barrier to consider is the researcher's prior knowledge, bias, and relationship with participants. Researchers' perceptions, experiences, and biases are another potential issue. As Cortazzi (1993) states, "the teller is not the only person telling the tale. The listener also shapes the story" (p. 21). How and what kind of questions are asked shapes how subjects respond. Each listener creates his or her interpretation and the telling is influenced by his or her reactions, questions, interests, and so forth. Moreover, Riesmann (1993) points out that in telling about an experience, a teller also creates a 
self-how he or she wants to be known by listeners. The process of telling is complex and involves multiple layers of ambiguity and selectivity. It is necessary to be cognizant of this interactive nature when constructing the interpretation and conclusion. The student researcher's personal bias, perspective and experience could have affected interpretation of participants' responses. Due to the nature of the type of research conducted, subjectivity cannot be eliminated including selection of interview questions, actual interaction during the interviews, to interpretation of interview contents. In addition, the student researcher worked in the central administration and was intimately involved in the curriculum transformation which could have affected the participant' responses. It could have inhibited truth telling by participants as some of the interview questions were directed to the central administration and could have been perceived as sensitive topics. Assumptions can be made some junior faculty may have not felt comfortable sharing their opinions in this context; hence providing socially acceptable answers. Having a neutral party who was not associated with the central administration may have been a better choice for the role of interviewer.

Narrative analysis is based on a postmodernist paradigm in which subjective epistemology is an underlining assumption. Moreover, as Cortazzi (1993) states the "analyst can never have access to all the knowledge for interpretation which participants themselves have" (p. 26). Riessman (1993) also shares this view. This could be seen as a limitation; however, as explained in the rationale section, through co-creation and meaning-making, researchers can make necessary adjustments to attain understanding. Researchers must also be aware of missing information. Although the study aimed to gain 
deep understandings of the faculty perspectives, there had to be conscientious recognition of uncovered information. This fluidity was an essential part of narrative analysis.

Lastly, the study was done at a single medical education institution with a small purposeful random sampling of seven faculty participants. Although governed by the same accreditation entity, each medical educational institution has unique organizational, cultural and financial structures, hence applicability and utility of the findings from this study may be limited.

\section{Summary}

This narrative analysis was used to explore medical education faculty perspectives by conducting interviews as a means of collecting data. The current study aimed to examine faculty perspectives on and engagement with medical education curricular revisions. Specifically, the purpose of this study was to explore motivational factors, both intrinsic and extrinsic, that contributed to adopt changes who were the early adopters of the curriculum transformation at a northwest medical institution. Data was transcribed and coded using initial coding in order to derive themes and conduct a thematic analysis. 


\section{CHAPTER 4: Results and Analysis}

The purpose of the study was to explore intrinsic and extrinsic factors that contribute to medical faculty engagement in curriculum transformation. According to the finding presented in the Association of American Medical Colleges website, over $84 \%$ of U.S. allopathic medical schools are in planning, implementing or have completed curriculum change: $34.7 \%$ reported that they were in the midst of planning stage, $30.6 \%$ reported that they were in the implementation stage and $19.1 \%$ reported curriculum change implementation had been completed in the past three years (AAMC, 2018). Faculty play a key role in all aspects of curriculum revision from development, implementation, and evaluation (Keating, 2014, Thomas, Kern, Hughes, \& Chen, 2016); therefore, engagement from faculty is essential to curriculum transformation. With more than $80 \%$ of medical schools in various stages of curricular revision, gaining an in-depth understanding of motivational factors of faculty participation in curriculum transformation contributes to both current and future practices of medical education. This study specifically looked into what factors foster medical education faculty to adopt curriculum changes. It explored both intrinsic and extrinsic factors that contribute to medical faculty engagement in curriculum transformation.

This chapter is organized into three sections: intrinsic motivation, extrinsic motivation, and overall findings and interpretation. The interview results will be categorized using Rogers' model of intrinsic and extrinsic factors (Rogers, 2003). Rogers' five perceived attributes of innovation (relative advantage, compatibility, complexity, trialability, and observability) will be referenced to categorize intrinsic 
motivation factors of the faculty participants. Relative advantage refers to the degree to which innovation is perceived as better than the idea it supersedes. Compatibility refers to the degree to which innovation is perceived as compatible with existing values.

Complexity refers to the degree that innovation is perceived as difficult to understand. Trialability refers to the degree in which innovation may be explored and tried without extended efforts. Lastly, observability is referred to the degree in which innovation is visible to others.

In addition to the five perceived attributes, four external factors, type of innovation-decision, communication channels, nature of the social system, and extent of change agent's promotion effort will be used to describe factors that affect the rate of adoption. Rogers defined three types of innovation-decision. An optional innovationdecision allows each individual to take almost complete responsibility for making an adoptive decision, whereas collective innovation-decision seeks consensus among the members of a system. These types of innovation-decision usually take time, slowing down the rate of adoption. In contrast, an authority innovation-decision may produce the fastest rate of adoption since an individual has no say in the decision to adopt the innovation. The second factor, communication channels affect the rate of adoption. Rogers argues that a high level of communication channels affect the rate of adoption and communication through interpersonal channels, compared to the one through media, is more powerful. The third factor, nature of the social system either inhibits or accelerates the rate of innovation adoption. Lastly, Rogers argues that a change agent's promotion effort affects the rate of adoption. A change agent tries to influence and steer an 
individual or unit toward adopting new ideas. The roles of change agents range from developing needs for change, establishing rapport with individuals or units and motivating them, diagnosing problems, and stabilizing changed behaviors. The following segment will use Rogers (2003) five perceived attributes of innovation and four external factors to report and analyze the findings of the current study.

\section{Intrinsic Motivation}

\section{Relative Advantage}

The first attribute, Relative Advantage was used to analyze faculty participants' perception of the curriculum transformation as improvements and would be advantageous to themselves, students and the program. Interview questions centered on their ideas of effective learning methods and whether or not they felt the direction of the curriculum transformation was beneficial.

Participants were asked about the benefits of incorporating the type of active learning methods and why it was better than traditional teaching methods such as simply giving a lecture. All seven faculty participants shared their thoughts on this. The faculty participants pointed out on benefits active learning methods have on learners. "People learn better when they have to apply information" (Faculty 3). This faculty used casebased scenarios to provide context to the basic science mechanism and fundamental knowledge. Faculty 7 described his experience with case-based learning as follows: "instead of memorizing, it forces students to think about why." He described a pitfall of traditional lectures as follows: 
What's on the slide, gets tested and what gets tested then gets learned and what gets learned then put into practice. But that didn't necessarily we weren't certain that [learning] was actually taking place. And I can honestly tell you based on my own experience that was not taking place (Faculty 7).

Other faculty described as active learning as "I felt like it was a way for students to question their own understanding of a concept that I hoped that they would come out on the other end solidifying learning" (Faculty 1). Faculty 5 described his experience with clickers:

With clickers, I was very skeptical about it when I first heard about it. Doing a clicker session during the course of lectures, it is tricky. I can't expect them to retain too much. My [clicker] questions are pretty simple, often times, it's too simple. Sometimes the students for very good reasons will pick a different answer than I expected. And then we can talk about why that might be true, in some context. So we, it's a nice interactive tool.

The feedback I get is positive. In a way, [clicker questions] serve as positive reinforcement [to the students] (Faculty 5).

Other participants described the benefits it has on them as educators: "It challenges me to think about the content from different perspectives" (Faculty 6); "It's fun! (Faculty 3).

As described above, the faculty participants perceived curriculum transformation and implementation of active learning methodologies to be advantageous. Although the faculty participants' responses varied in terms of a beneficiary of the active learning 
method, they were able to articulate their perceptions related to relative advantage. A similar concept of relative advantage is discussed in the Technology Acceptance Model which asserts the perceived usefulness of innovation affects its adoption (Davis, 1989). Davis argues that perception of the usefulness of innovation is essential; put differently, even if an innovative technology is easy to use, people are more likely to adopt the innovation if they perceive it as beneficial or advantageous. Both Davis and Rogers stress the importance of perceptions. In this sense, the interview results from this study suggest the faculty participants believed that the curriculum revision was advantageous over the preceding one. The attribute, relative advantage, is a key element in an adaptation of innovation as Rogers (2003) argues that it is one of the strongest predictors of rate of adoption. Another aspect to consider when reviewing the relative advantage is the concept of incremental innovation. "An incremental innovation (that is, non-preventive) innovation provides a desired outcome in the near-term future" (Rogers, 2003, p. 234). Although the current study did not specifically explore the concept, one could make assumptions that the faculty participants perceived that the designed consequences and benefits of adopting active learning methods to be near future.

\section{Compatibility}

The second attribute, Compatibility was used to examine the degree to which faculty participants' pre-existing values were in line with the curriculum transformation. The participants were asked about the role of the basic science curriculum in medical education, the role of instructors, and whether or not they have had learner-centered education experience as a learner. 
Not surprisingly, none of the seven participants responded having to have had learner-centered education experience as Faculty 1 described his educational experience "... one person standing up in front of the classroom and talking to a room full of people, and I'm taking notes and so totally traditional." However, when asked about their perception of the role of an instructor, all provided similar responses that emphasized learning than teaching. "Instructors are there to facilitate learning but not necessarily deliver the knowledge" (Faculty 2). We are teaching students to teach themselves (Faculty 4). Faculty 5 highlighted not only teaching but ensuring attainment of knowledge.

The role of instructors is to figure out what the students need to know, figure out how to deliver the content in a way that they can understand and then do my best to make sure they understood. And anything that I do that helps those functions is good and anything that I do to get in the way of those functions is not" (Faculty 5).

Faculty 7 illustrated instructor's role as a guide:

Making students excited about the topic itself. Most students have access to a much broader array of potential information in their textbooks. I provide perspective in what things at least I think are important in that broader array and so partly is to organize topics and concepts related to them that will be useful to them (Faculty 7).

Faculty 1 also explained his role as an instructor similarly to Faculty 7 but also pointed out the importance of knowing where learners are. 
Provide a superstructure to help them categorize information. So the term I've used in the past is that I'm putting up the Christmas tree and they're gonna put the ornaments on. I don't try to get too far in the weed. But it depends on where the learners are (Faculty 1).

Faculty 6 also explained putting a focus on learners: "the first thing is to put yourself in their place, so you are seeing from their perspectives, you'd align where they are, then you can lead."

Faculty 3 shared her core belief in teaching. It's the difference between me going and saying I stood up there for an hour talk at the students and I did my job and saying we assess them and they actually understood my content. If the goal is for them to learn that is very different from the goal of having me teach (Faculty 3 ).

These comments demonstrate compatibility of values they hold to the essence of curriculum transformation which include shifting of faculty roles from traditional one where "the instructor feeds information to students in a lecture or PowerPoint slide presentation format" to "guides or facilitates student learning through direction to resources and stimulation of discussions" (O’Neil, Fisher, and Newbold, 2009). Despite the fact they all experienced teacher-centric education in their formal education through their K-12 to higher education, all seven participants expressed their belief that is incongruent with one teaching-learning fits all model. 


\section{Complexity}

The third attribute, Complexity was used to explore the faculty participants' perception of how difficult they deemed when adopting the changes in teaching methodologies.

The faculty participants were asked to describe learner-centered education and whether or not they have had formal training in active-learning methods.

When asked to describe what learner-centered education was to them, various answers were given except for Faculty 1 who answered that he did not know. Faculty 2 used the term, "meaningful changes in learners" to describe learner-centered education. He also described issues with lectures as:

You don't actually know that people have learned what it is that you thought that you taught them. So you can say the words and you can put it on the slides, but it doesn't actually mean that it reaches the learners (Faculty 2).

Faculty 6 mentioned about an importance of placing a focus on learners and understanding of the audience's knowledge level and needs.

How to focus on audience, their focus is different than yours. Meet people where they are. You might talk about the same subject but the delivery should be different. Instructors should be focused on teaching materials at the level of the students are engaged in (Faculty 6).

Faculty 7 shared a similar idea as Faculty 6 on learner-centered education. He stated he adjust his content based on each class. 
As to whether or not they have had a formal training in active-learning methods, all responded with experiencing some level of training. Faculty 7 described the time he participated in the team-based learning workshop. "The workshop itself was done in a team-based model. We were given pre-workshop assignments and did individual and group...can't remember what they are called...the quiz" (Faculty 7). Faculty 2 and 3 stated that they have attended various workshops.

Rogers (2003) asserts "any new idea may be classified on the complexitysimplicity continuum" (p. 257) and if innovation is perceived more toward the complexity spectrum, slow the adaptation. He uses diffusion of home computers to illustrates his point: at the beginning, only technically savvy hobbyists originally adopted home computers as the earliest model had a high-level of complexity that the general public simply did not understand. This caused a slow diffusion of home computers in the 1980s. Similarly, team-based learning was viewed by the faculty participants as too complex. Despite the administration's efforts to provide faculty development opportunities to diffuse this particular type of active learning methodology, it did not result in widespread diffusion. However, most faculty participants were able to explain what learner-centered education means to them which is the essence of curriculum revision to change the needle from teacher-centric education to learner-centered one, Although verbalization of their understandings alone does not fully demonstrate whether or not the faculty participants viewed learner-centered education as less complex, it at least indicates they understood an essence of the concept. 


\section{Trialability}

The fourth attribute, Trialability was used to examine whether or not the faculty participants felt they were able to try new learning methods on a much smaller scale. As Rogers (2003) pointed out, the perceived possibility of small-scale trials is critical in faculty to understand the potential benefits.

The faculty participants were asked if they tried using a simple, easy to implement active learning method when they started to implement.

Faculty 1 described his thought process when faced with implementing active learning and the creation of a concept map.

Active learning... I like the concept of it. But I couldn't find the time, it was a matter of efficiency. There are so few hours in any giving course. To break up an hour into active learning, all sounded great but I didn't have time to do it. I came up with a concept map as one of the ways to do it.

Faculty 3 recollected on the session that taught her a simple yet powerful educational technique and based on the workshop, she began implementing it: Active learning doesn't have to be a grand scale. What is called 'think-pairshare"? So she did that with us and it was fantastic because she had a question up and she said I want you to partner with somebody and you want to think about what your answer is, you're gonna turn to your partner, and you are gonna say I think it's this or it's that, and you have to put your money down before you get your answer and share your answer and commit to each other...It forces people to 
say out loud what they think. I think the part that we have to explain your reason to your partner is where the learning happens (Faculty 3).

Faculty 2 shared about his experience in trying out basic but yet effective technique when delivering a didactic where he inserted two specific slides. The first one to state learning objectives and the last one to restate and reflect back what you learned. Just the simple notion of it to the case example or emphasize why it is that it's clinically, whatever it is that you're learning that is clinically relevant, testing your learning objectives, teaching that material, and then re-reflecting back. So this is what you learned today it was brilliant (Faulty 2).

Additionally, he stated that he uses a lot of videos, films and sometimes have students read comics to reinforce the content area. Faculty 7 also used short clips from movies. But her reason was different from Faculty 2. "People learn differently. You can't expect all of them to learn from reading, watching us talk at them for an hour."

Rogers (2003) asserts "if an innovation can be designed so as to be tried more easily, it will have a more rapid rate of adoption" (p. 258). To this end, Bennett and Bennett (2003) conducted a study on the adaptation of instructional technology by faculty and concluded the importance of providing an opportunity to "test drive" innovations. In the preceding section, one of the faculty participants pointed out team-based learning active learning methodology. Clearly, one can argue a notion of trialability impeded adoption of team-based learning compared to other methods such as think-pair-share or utilization of video clips that were perceived as high on trialability. 


\section{Observability}

The fifth and last attribute, Observability, was used to examine whether or not the faculty participants had opportunities to watch other faculty adopting new learning methodologies. Rogers (2003) argues that Observability affects the adoption of innovation.

The faculty participants were asked if there were any colleagues who were using active learning methods.

All seven faculty participants had experiences observing other faculty conducting lectures or workshops using active learning methods. Some experienced through observing other faculty teaching students while others experienced as students in active learning faculty development sessions. Faculty 7 recollected observing another faculty.

I watched how he taught biology, and he was a combination of very strict... but also he was very creative he would come to class and do funny little show-andtells to get the student's imagination going, and he tried various different gimmick's to try to get the students to see things in different ways, and I realized that was very effective that he was stepping away from just PowerPoints and very quickly, given the students humorous, but somewhat effective models to help them understand concepts (Faculty 7).

Faculty 6 sat in her colleague's lecture where clicker questions were used. "I wanted to see how they worked in action. Every single one of the students was paying attention and participating...I realized this is powerful." 
Faculty 3 and 4 both attended faculty development where some of the active learning methods were demonstrated and took away different components and started incorporating them. Faculty 3 recalled the term she learned from the workshop, Primacy and Recency Effect. "People remember what was said at the very beginning and at the end and they can't remember the middle exactly, and I was like, no wonder nobody gets what I'm saying. It was just mind-blowing." Faculty 4 remembered the usage of a simple, yet powerful modality of case-based learning. "Instead of memorizing the fact, students can see the utilization."

According to Rogers (2003), "the observability of an innovation, as perceived by members of a social system, is positively related to its rate of adoption (p. 258). Similarly, Parisot (1997) asserted peer observation to be one of the key motivational factors in the adoption of innovations. Observation can occur in an authentic environment or through faculty development workshops that use active learning methods. Perhaps a key factor she makes is the ability for potential adopters to observe peers "within the immediate sociocultural group" (p.10). In other words, observing a so-called educational expert delivering an active learning method may not have as effective influence as observing someone who is considered as peers who share similar traits, experiences, or values.

\section{Intrinsic Motivation Summary}

In this section, based on Rogers (2003) five attributes, the faculty participants' intrinsic motivations were analyzed. As Rogers pointed out "getting a new idea adopted, even when it has an obvious advantage, is difficult" (p.1), the current study indicates 
these five attributes interplay and explain the intrinsic motivation of the faculty participants who were identified as early adopters of the curriculum revision. All faculty participants perceived learner-centered education and active learning methodology to be beneficial and felt compatible with their existing values; however, in terms of their past education experience, all stated that they had teacher-centric education. The faculty participants' answers varied when asked about what learner-centered education means to them, but the essence of their answers signified they clearly saw benefits of the curriculum revision and application of active learning methods. In terms of complexity and trialability, this study found that the active learning methods that were viewed as rather simple and easy to try were successfully adopted by the faculty participants while an active learning that was viewed as complex, hard to learn and implement, and timeconsuming failed to diffuse despite the change agent's promotional efforts. In regards to an attribute, observability, high visibility contributes to diffusion but if innovation is complex or potential adopters are unable to easily try on a small scale, this attribute alone would not diffuse adoption of the innovation. As aforementioned, the study found interconnectedness of the five attributes Rogers (2003) defined. In the next section, the other four variables he defined will be used to analyze extrinsic motivation factors.

\section{Extrinsic Motivators}

Rogers (2003) identified four external factors that affect the adaptation of innovation: type of innovation-decision, communication channels, nature of the social system, and extent of change agent's promotion effort. In this section, the interview questions around extrinsic motivators will be examined. 


\section{Type of Innovation-Decision}

Rogers (2003) describes three types of innovation-decision: optional, collective and authority. Interview questions were structured to discover the faculty participants' perception of the curriculum transformation decision. Rogers argues that compared to collective and authority types, optional decision-making allows individuals to take responsibility in decision making, in turn, speeds up the rate of adoption.

One's sense of control plays a crucial role in motivation, hence affecting the rate of adoption. This is true especially in the higher education institutions where faculty autonomy is viewed as a fundamental element (King \& Boyatt, 2015). Lyness, Lurie, Ward, Mooney, and Lambert (2013) and Huun and Hughes (2014) also discuss the importance of autonomy in relation to faculty motivation in medical education.

The faculty participants in this study were asked about their perception of the curriculum revision, specifically on whether or not they felt pressured from organization, department or administration to change the ways they have been teaching or to participate in the curriculum revision. In addition, they were asked if they felt the curriculum revision initiative was top-down or consensus of faculty and administration.

Overwhelmingly, the faculty participants felt that the decision and initiative to revise curriculum came from the administration as Faculty 1 pointed out, "it wasn't like a groundswell of faculty [who initiated the curriculum revision]." One faculty stated, "I still don't know why we had to change the curriculum, maybe accreditation?" (Faculty 6). Faculty 5 stated, 
The very first meeting we had, a question came up why we are considering revising the curriculum 'cause we are doing so well. Great, we are doing well, let's figure out what we are doing well and improve on it for better. Who can argue with that? And instead what happened was throw the baby out with the bathwater (Faculty 5).

However, when asked if they felt pressured to participate in the revision processes or teaching, they all agreed that there was no external pressure to participate from the central administration, their departments, or other organization as Faculty 5 put it, "I still saw this as my responsibility. I think it's important. I can do well.” Faculty 6 stated, "you are never pressured to participate. I wanted to." Faculty 2 summarized the transformation as "top-down inspiration with bottom-up efforts." Faculty 6 shared her perspective on the top-down decision on the curriculum revision. "There has been a lot of suggestions from the top that I find them very productive. We as a teacher, we think we know everything. You have to be always open to learning something new."

The findings in the current study is interesting and demonstrates complexity of medical education structure and organization; unlike most of higher education where teaching is a required component of faculty members, many faculty members at medical education entities may have options to participate as little as possible in teaching mission and dedicate their time in either clinical or research mission. Although the faculty participants' responses allude to what Rogers describes as authority innovation-decision, the faculty participants were not forced to or pressured into participating in the new curriculum. Rogers (2003) describes the types of innovation decisions range to be a 
continuum. In the case of the current study, authority and optional innovation-decisions both played a part.

\section{Communication Channels}

According to Rogers (2003), a high level of communication channels affects the rate of adoption. He describes communication through interpersonal channels, compared to the one through media, is more powerful. It is crucial to examine the way and processes as well as from what source the communication was delivered to the faculty participants in order to understand extrinsic motivators.

School-wide town hall and multiple Q\&A sessions were held and both internal and external websites that explained the transformation was created at the time of curriculum revision. The faculty participants were asked what they remembered about the communication on the revision. They were asked whether they felt the reasons to revise the curriculum were clearly communicated to them, and how the change communicated.

The faculty participants' answers varied. 'No, no, I don't know that I know the reason...I don't remember what the discussion was. It would've been helpful to visit all departments... These are the sort of major structural change and why we need to make them" (Faculty 2). Faculty 7 attended the meeting where the role of faculty was discussed:

Well, I think the main changes that were communicated to me we had to do with the content and structure of the curriculum itself, we did not get for the most part, at least initially, we didn't get into the details. We got more into what the week 
was gonna look like for the students, and what are relative, what our respective roles would be on in different settings (Faculty 7).

Faculty 2 remembered about the town hall where the curriculum revision was described as "ripping the bandage off fast is really important because otherwise, it will never happen." Faculty 4 remembered getting the information from the website. Faculty 5 had many of his colleagues participated in the initial planning of curriculum revision; therefore, he had in-depth knowledge of process and progression which he described as horrid. Faculty 1 recollected about the meetings he attended:

Oh yeah, there were group meetings, and they started with a pretty general but most of the meetings that I remember, had more to do with content areas where we would have a teetering on the which level we were dealing with. It might be a room full of people who had a common interest in let's say renal disease. So we had people sometimes in the room we were also trying to negotiate with... there's a lot of negotiation for a time, the amounts of curricular time (Faculty 1). The interview results illustrate what Bolman and Deal (2003) call winners and losers. The curriculum revision created opportunities but also created a sense of loss and disruption among some faculty members as Faculty 1 and 5 described. Interpersonal communication channels allow interactions between change agents and adopters as well as among adopters and others to "create and share information...to each a mutual understanding" (Rogers, 2003, p. 18). The communication channels can be utilized not only to share benefits of curriculum revision but also could inhibit people from adopting innovations depends on which side of the fence they are in. Bridges (2009) argues the 
importance of managing an ending. He asserts that people must be allowed to reconcile their own personal endings and that the change agents are to recognize their losses and feelings and emotions that are associated with their losses. Management of endings is as important as the presentation of innovations. In addition, the interview discovered that the rationale for curriculum revision was unclear to some faculty members. To this end, Rogers (2003) suggests change agents assess the felt needs of clients which include carefully generating needs and using communication channels to disseminate.

\section{Nature of the Social System}

Although faculty autonomy is a fundamental component of the higher institution, faculty still are under constraint of what Rogers (2003) call Norms. Norms play a key role as it is viewed as behavioral standards that are shared by members of a social system.

The faculty participants were asked about the value of teaching in their departments and how they view the institution's stance on the culture of innovation. All faculty participants agreed that their departments value teaching; however, all similarly agreed that the value placed was not as high as other priorities such as having a big grant. Faculty 5 stated that teaching was part of being faculty but regardless, he would do it "cause it's important."

Faculty 7, when asked whether or not the institution has a culture of embracing changes, he responded as follows:

Some areas yes and some not. Changes are good. Productive changes, appropriate changes are good. Sometimes it's difficult. You worry, but sometimes you have to make the decision and you live with the decision for a 
short time and look at the outcome before you reject it. I think most of us are hostage to our own success. In it, we are always looking for perfection which becomes delusion and we can't move forward. There is no such thing as perfection. Good and excellent should not be the enemy of perfection (Faculty 7). According to Rogers (2003), "the social and communication structure of a system facilitates or impedes the diffusion of innovations in the system" (p. 37). In the current study, it was found that the social system in this institution had a baseline value system that was shared among the community. All faculty participants expressed their views that teaching is valued by their respective departments and the norms served as "a guide and standard" (p. 26) in participating in the curriculum revision as early adopters.

\section{Extent of Change Agent's Promotion Efforts}

According to Rogers (2003), promotional efforts by a change agent influence an individual or unit adopting an innovation. The roles of change agents range from developing needs for change, establishing rapport with individuals or units and motivating them, diagnosing problems, and stabilizing changed behaviors (Rogers, 2003). The faculty participants were asked about the national- and institutional-level promotional efforts. Specifically, they were asked how external organizations influenced the change in medical education at our institution and how important the influence was. In addition, the questions around resources including faculty development opportunities were asked.

When asked about external organization, none of the participants was able to articulate its influence on the curriculum transformation at this institution. When 
prompted about the grant from AMA, only one participant, Faculty 3, was able to recollect it. The interview results illustrate the void in knowledge and information among the faculty participants in terms of national-level promotional efforts.

As to faculty development sessions, Faculty 2 participated in the team-based learning workshop that was provided by the administration. He described the difficulty of team-based learning implementation. "I think like you're either in or you're not, or you have one track where this track's gonna do team-based learning...It has to be all or nothing" (Faculty 2). Ultimately, he did not incorporate a team-based learning mechanism.

Faculty 3 suggested giving more targeted development opportunities where specific feedback is given to faculty lecturers. Similarly, Faculty 2 suggested getting feedback not only through teaching effectiveness evaluation students fill out but also from educators or peers to give feedback on active learning. Faculty 6 proposed,

I think from start to finish, just watching somebody walk-through from building even following their intellectual journey and they're sort of the practical journey. How do other people do it? I just think, building, you're building the hour that you're gonna spend with someone is really a key skill (Faculty 6).

Faculty 7 illustrated the importance of the big picture and feedback mechanism as a part of faculty development. "You see the small picture, this was your lecture, these are the questions that you wrote, this was how well people did on that topic. This is how well people are doing on the boards." 
The findings from this study suggest the faculty participants perceived the innovation at the study site as relatively a centralized rather than decentralized diffusion system. In a centralized diffusion system, communications occur top-down which heightens the role of change agents in dissemination of appropriate and sufficient information. Rogers (2003) stated depending on the nature of innovation and social system, hybrid diffusion system can be formed. The sentiments gathered from the interviews were that the faculty participants viewed the curriculum transformation as something that had to be done but combining centralized and decentralized diffusion models could have facilitated the change in a less confusing and threatening manner. In addition, promotional efforts to disseminate national trends and data to better establish a shared understanding and foundation for reasonings to change among change agents, early adopters and adopters could have lessened perception of top-down change.

\section{Extrinsic Motivation Summary}

In the preceding sections, extrinsic motivational factors were examined using four variables Rogers (2003) identified. Each variable contributes to the innovation diffusion process. Rogers asserted two distinctive structures: homophily and heterophily. Homophily is "the degree to which a pair of individuals who communicate are similar" (p. 305), and promotes effective communication but "can act as an invisible barrier to the flow of innovations within a system" (p. 306) whereas heterophily is "the degree to which pairs of individuals who interact are different in certain attributes" (p. 306) hence communication may cause dissonance as individuals do not share the same understanding, belief, values, and common meanings. The current study found a blend of 
communication channels with both aspects from heterophily and homophily. In a heterophilious community, innovative ideas are encouraged whereas, in a homophilious one, stagnation may be embraced or tolerated. Faculty in higher education, especially in medicine are expected to advance the health of humans; in other words, they are expected to be innovative which corresponds with a characterization of heterophily. However, as described in Chapter 1, for over 100 years, medical education and its structure and delivery were relatively unchanged until recently which could indicate homophilious aspects of the community that harbors complacency. This poses challenges to change agents. Generally speaking, the findings from this study do not suggest an optimal approach to diffuse innovation in terms of extrinsic motivators. Although Rogers (2003) argues that authority innovation-decision type has the fastest rate of adoption of innovation, "authority decisions may be circumvented by members of a system during their implementation" (p. 29). In the current study, faculty viewed the curriculum revision decision type to be the authority, as evident in many of them unable to articulate the reasons behind the initiative to revise the curriculum. However, another layer to consider here is the fact not all faculty members in healthcare professional education entities are expected to or choosing to teach. In this sense, as previously discussed, the type of innovation-decision could be categorized as an optional one. In regards to the change agent's promotion efforts, many attended faculty development workshops for active learning but there seemed a void in their knowledge concerning national-level efforts to transform medical education. 


\section{Summary of Interpretation of Findings}

To answer the research question, what factors foster medical education faculty to revise their curriculum, the interview questions were organized using Rogers' (2003) diffusion of innovations theory. For the purpose of this study, five perceived attributes of innovations: relative advantage, compatibility, complexity, trialability, and observability were used as foundations to categorize and understand the adoption of the curriculum revision. To examine extrinsic factors that affect the adoption of curriculum revision, four factors, the type of innovation-decision, communication channels, nature of the social system, and extent of change agents' promotional efforts were used as structures. In this section, extrinsic and intrinsic factors that influenced faculty to adopt curricular transformation, specifically learner-centered active learning pedagogy will be analyzed.

One of the four factors Rogers defined and used in this study as a part of extrinsic factors is the type of innovation-decision. When asked about the type of innovationdecision, all participants expressed that they felt the curriculum revision decision was a top-down decision which corresponds with Authority Innovation-Decision - innovation decision made by people in power. Rogers argues that this type of innovation type yields the fastest rate of adoption, but the underline assumption is that people who are adopting the innovation do not have a choice to refuse adoption. In the case of this study, faculty participants had the freedom and choice to participate or not to participate in the curriculum revision. In other words, each faculty had the autonomy to make his or her decision. During the interview, a couple of participants reflected on losing good teachers or described as “casualties.” As Rogers pointed out, with Authority Innovation-Decision, 
compared to Optional Decision and Collective Decision, it produces a higher level of resistance. At the time of the curriculum revision, because of autonomy faculty members had, some of them simply decided not to participate. In this sense, to the faculty members who decided to not participate, although the type of innovation-decision was Authority, to them, the type of decision ultimately was Optional Innovation-Decision.

Communication channels and knowledge on a promotional effort by the change agent varied by the faculty participants. Some faculty participants had intimate knowledge of transformation including reasons behind it but others had a minimum insight. Some faculty participants felt congruent with the innovation and were fully on board with what they were hearing whereas the other felt his colleagues and what they had previously created were being disrespected and discarded. Some felt that there was a hidden agenda. Each faculty formed his/her opinion through town hall, small meetings, websites, and discussions with their colleagues. Their level of knowledge varied. Faculty development-wise, most faculty participants attended workshops. A simple yet effective active learning method such as think-pair-share which was used in the workshops was later adopted by the faculty participants. Their attitudes toward the curriculum revision and its process varied. Many faculty participants were not aware of the initiatives and involvement of national organizations. But in the end, regardless of communication channels and change agent's promotional efforts, these seven faculty participants chose to adopt the curriculum revision as early adopters.

Another element that affects the rate of adoption surrounds around the nature of the social system. Whether or not their respective departments support the teaching 
mission of the institution helps to create a norm within the departments. In most medical educational entities, there are three distinctive but correlated missions: education, patient care, and research. One can argue that education mission compared to the other two missions, yields the least incentive in terms of monetary value (Goulston, Oates, Shinfield, \& Robinson, 2012; Jones \& Korn, 1997). In this study, all participants stated that their departments value teaching. Although some felt that the importance of teaching could be perceived as secondary to either research or patient care mission depends on their departments, all felt that they had some level of autonomy in choosing to participate in an education mission of the university. The findings from this study suggest that departments are supportive of their faculty participating in an education mission and faculty feel they are supported in their decision to participate.

As to intrinsic motivation, Rogers' five attributes were used to examine factors that influenced faculty to adopt curricular innovation. According to Rogers, innovation is more likely to be adopted when people believe that it yields some relative advantage. All faculty participants in this study expressed their views on the benefit of active learning modalities compared to didactic-centric teaching. Many described the benefits active learning has on learning: application of information; providing context; opportunity for learners to question their own understanding; and solidifying learning while others pointed out benefits to educators. For instance, one faculty stated that it allows her to think about the content from different perspectives. Faculty participants in this study clearly felt incorporating active learning methodologies was advantageous and beneficial to learners and/or to themselves. 
The second attribute we examined was comparability. According to Rogers, innovation is more likely to be adopted if pre-existing values are in line with it. Although the faculty participants did not experience learner-centered education while they went through their formal education, when asked about the role of instructor, their descriptions were far from the teacher-centric view where delivery of content is the focus. One faculty participant stated the ultimate goal of education is to teach students to teach themselves. Although the faculty participants' responses varied, they all embraced the idea of learnercentered education which was a core element of curriculum transformation. The belief that active learning is beneficial, accompanied by their preexisting values - comparability on learning and teaching seems to strengthen the faculty participants' intrinsic motivation to adopt the curricular revision.

Along with relative advantage and comparability, complexity and trialability appear to have affected the faculty participants' adoption of active learning methodologies. In terms of team-based learning, it was viewed as difficult and timeconsuming to adopt whereas clicker questions and think-pair-share active learning methods were viewed as effective and easily implementable. Both think-pair-share and clicker questions were used by multiple faculty participants. They expressed one of the benefits of using clicker questions is gauging where learners are in terms of comprehension of a content area. In addition, the faculty participants expressed the benefit of anonymity that is afforded when students post their responses using clickers. Interestingly, one faculty stated that the anonymity aspect was the reason why she preferred a think-pair-share modality where it forces students to commit to their 
responses and explain the reasons behind it. Although clicker questions are viewed as lower-end of the complexity spectrum, one faculty stated that he was unable to use clicker questions due to a technical issue where he used his laptop computer to present and was unable to display students' responses. Along with complexity and trialability which contributed to the faculty participants' intrinsic motivation to adopt active learning modalities, observability of active learning methods was noted by them. Seeing others use active learning modalities or for some of them experiencing it through workshops gave the faculty participants the effects of active learning methods has on learners. As one of the participants stated upon observing his colleague use clicker questions "every single one of the students was paying attention and participating...I realized this is powerful"(Faculty 6). As Rogers (2003) stated, visibility is crucial so observability can contribute to one's degree of relative advantage. It should be noted that despite innovation is visible, a high degree of complexity and low level of trialability may negatively affect innovation adoption. Case in point, team-based learning that was a part of the focal of the curriculum revision failed to take off despite the administration's effort to promote its implementation. As team-based learning workshops were held, many faculty participants witnessed and experienced its modality; however, unlike aforementioned clicker questions or think-pair-share, high complexity and low trialability of team-based learning resulted in not getting buy-in from the faculty members. Simply put, it was viewed as hard to use and implement.

Faculty development opportunity wise, opinions differed. Some felt that a more individualized approach, for instance, having opportunities to receive feedback on their 
sessions from educational experts would benefit while others felt more of the generalized group setting approach of faculty development would be helpful. Yet another felt having a loop back mechanism would be helpful which include an evaluation by students but also how well students performed on tests and exams.

In summary, when conducting curriculum overhaul, institutions must first review norms and shared understanding among central administration, departments, and faculty. In the case of the institution the current study was held, underlining of the success with having motivated faculty participants in the new curriculum could be attributed to existing shared values with teaching. Although not all faculty participants shared the same understanding in regards to reasons behind the curriculum transformation, ultimately this shared belief along with their own belief in learner-centered active learning education motivated the faculty participants to partake as early adopters. Providing faculty development opportunities that are preferably conducted by their peers who champion a simple and efficient yet effective active learning method is an effectual way to permeate transformational efforts. The delivery of faculty development can be as simple as giving faculty members an opportunity to observe classroom to holding workshops using an active learning method. 


\section{CHAPTER 5: Discussion and Conclusion}

The purpose of this study was to examine faculty perspectives on and engagement with medical education curricular revisions, specifically to explore motivational factors, both intrinsic and extrinsic, that contributed to adopting changes who are the early adopters of the curriculum transformation at a northwest medical institution. Qualitative research was conducted at one of the northwest comprehensive health science education institutions. Seven faculty were interviewed. Interview questions were established and coded using Rogers (2003) diffusion of innovation model. This chapter contains a summary of findings, implications and recommendations, suggestions for future research, and conclusion.

\section{Summary of Findings}

\section{Extrinsic Factors}

The first research question this study explored is extrinsic factors that influenced the faculty participants to adopt curricular transformation, specifically learner-centered active learning pedagogy. In this study, Rogers (2003) four factors, type of innovationdecision, communication channels, nature of the social system and extent of change agent's promotion efforts were used to analyze the faculty participants' extrinsic motivational factors. The current study found that the faculty participants perceived the curriculum transformation initiative to be an authority innovation-decision type where "adopting induvial has no influence in the innovation-decision" (p. 29). This was evident through the faculty participants' comments such as “it wasn't like a groundswell of faculty" (Faculty 1) and "I still don't know why we had to change the curriculum" 
(Faculty 6). From the comments shared by the faculty participants, one may conclude that the faculty participants had no options but to adopt the innovation; however, all had options to participate or not to participate. In this sense, the decision type was inclined more toward optional decisions on a continuum. Although the faculty participants' departments embraced teaching, as one faculty pointed out that other pillars of the university such as research and patient care missions are weighed relatively heavier than the education mission. The above comments also indicate the change agent's promotion efforts including communications were not received by the faculty participants. Faculty development opportunities provided by the change agent seemed to help the faculty participants' views on active learning and in some cases, directly helped them to adopt new active learning methods. Among extrinsic factors that were examined in detail in this study, departmental norms that value teaching and faculty development opportunities seemed to have a positive effect on extrinsic motivations.

\section{Intrinsic Factors}

The second research question asked intrinsic factors that influenced the faculty participants to adopt curricular transformation, specifically learner-centered active learning pedagogy. All five attributes Rogers (2003) identified appeared to have factored in the faculty participants' decisions to participate in the adoption of the curriculum transformation to some extent. Although Rogers surmised that "relative advantage and compatibility are particularly important in explaining an innovation's rate of adoption (p. 17), the current study found that a combination of complexity, complexity, and observability appeared to have affected in their decisions to participate in the curriculum 
transformation along with relative advantage and compatibility. Both Davis (1989) and Rogers asserted that perception of benefits and usefulness of innovation is essential to the adoption of innovation. To this point, all faculty participants in this study articulated their views on relative advantage. Some participants expressed that learner-centered active learning methods to be beneficial to students' learning such as application of information, solidifying understanding, positive reinforcement, and memorization to metacognition. Two faculty participants stated benefits it has on them as educators: challenges them and simply put, fun. Knowing where learners are in terms of their understanding as educators were also pointed out during the interviews. In regard to the three attributes, complexity, trialability, and observability, the current study indicates the simplicity of active learning method including ease of trial were important factors. In addition, the point Rogers (2003) made in regards to importance of interpersonal communication with near peers about an innovation was evident in this study in terms of observability where the faculty participants shared their experiences observing others like them (near peers) teaching using active learning methods which seemed to contribute to them adopting innovation.

\section{Best Practices}

The third research question asked about the best practices of learner-centered active learning methods. Case-based learning, concept map, video clips, think-pair-share, chunking methods, stating objectives, teach, then restate what was covered, and incorporating clicker questions were shared by the faculty participants. They found these active learning methodologies to be simple yet effective. As faculty are all pressed with their time, it was extremely hard for them to learn and utilize team-based learning 
methods despite the change agent's efforts in delivering numerous faculty development sessions on it. One thing to note is the need for the central administration to provide ample technical support. Despite the ease of use of clicker questions, one faculty notes the technical difficulty he faced which could have addressed by the administration.

\section{Organizational Support}

The fourth and last research question asked for the faculty participants' suggestions as organizational supporting factors for curricular transformation. In general, the faculty participants enjoyed and valued group-setting faculty development opportunities. However, a faculty participant suggested having more tailored, individual, feedback-based faculty development. Just as learners wish to receive feedback to identify an area of deficiencies in order to improve their performance, so as faculty members. Having a loop back mechanism where faculty members can obtain not only student feedback on a session but also how well students performed in tests and quizzes on the content area taught by the faculty would be helpful. As there are so many educators involved in a course, each teacher does not see the overall performance of students as well as where his/her session fits in an overall big picture of medical education. Having access to a big picture help faculty members understand where learners are in terms of knowledge and understanding of content areas. While providing faculty development opportunities to further promote and share best practices of active learning, the administration also should place a focus on making a platform or data on a big picture accessible to faculty members. 


\section{Implications and Recommendations to Change Agents}

As noted previously, over $84 \%$ of U.S. allopathic medical schools are in planning, implementing, or completed curriculum change. Faculty play crucial role in curriculum revision. Successful planning and implementation of a new curriculum affect many lives including faculty, students, and administration, but ultimately down the road, patients. The current study explored intrinsic and extrinsic motivational factors of faculty members who were identified as early adopters of the transformed curriculum. Uncovering factors associated with the adoption of the new curriculum by these early adopters sheds light on faculty perspectives and findings can be used by other medical schools that are planning or undergoing curriculum revisions to facilitate transitions.

\section{Recommendation 1: Transition Management and Communication}

Although there is no right and wrong way to conduct curriculum revision, an initiator of change must acknowledge a sense of loss for the ending of the preceding curriculum and create an opportunity for bilateral communication for faculty members to express their losses. The change agents must examine potential consequences of curriculum revision and identify "winners and losers" (Bolman and Deal, 2003) in order to anticipate conflict and its impact. In a case of large-scale curriculum transformation, the change agent, not only must consider the impact of the change on individual faculty but also consequences it may have on an organization's culture, shared value and norm. As in learner-centered education where one-size does not fit all, transition management is highly depended on each organization. If possible, creating an opportunity to form a community of interested members and invite the change to emerge from the community 
rather than top-down, pre-planned strategy would contribute to a positive and "a significant impact on the relational culture" (Cottingham et al, 2013). This point is similarly illustrated by Rogers (2003) as well.

Change agents may seek to generate needs among their clients, but this must be done carefully or else the felt needs upon which a diffusion campaign is based may be a reflection only of the change agent's needs, rather than those of clients. Thus, one dimension of compatibility is the degree to which an innovation is perceived as meeting the needs of the client system. When felt needs are met, a faster rate of adoption usually occurs (p. 246).

According to Rogers, communication is a process that creates and shares information to reach a mutual understanding. Shared vision is one of the key components of successful planning and implementation of curriculum transformation. The findings from this study suggest the faculty participants were aware of the goals of curriculum transformation but many could not articulate the reasons behind the changes which created some level of distrust toward the administration as illustrated in the comments such as "throwing the baby out with bath water." In addition, many participants were not aware of the national movement and involvement. Administration (or change agents) must engage faculty members by both mass and interpersonal communications early on in part to apprise them of any signs of progresses and pertinent information but more importantly, to create purposeful, shared felt needs. Administrations should never assume faculty members share information with which they may have access. Providing a big picture including national trends and movements while clearly stating institution-specific 
reasoning behind the change using an evidence-based approach, over communicating processes and progress, and providing opportunities for faculty members to express their concerns are keys to s successful implementation of curricular change.

\section{Recommendation 2: Identification of Early Adopters}

The faculty participants in the current study believed that the curriculum transformation, specifically the implementation of active learning methods, was beneficial. This was demonstrated by comments such as "people learn better when they have to apply information" (Faculty 3) and "instead of memorizing, [active learning] forces students to thing about why" (Faculty 7). This study found that identifying faculty who perceive the curriculum revision to be better than the one it supersedes (relative advantage) and consistent with their existing values (compatibility) are key elements to a successful implementation of curriculum revision.

Faculty in this group can provide communication channels to other faculty members as Rogers (2003) asserts that "more effective communication occurs when two or more individuals are homophilous" (p. 19) and those individuals evaluate an innovation "based on the subjective evaluations of the innovations conveyed to them by others like themselves (peers)" (p. 247). Institutions can identify faculty in this group first through tracking attendance of informational sessions and faculty development opportunities and approach them on individual bases to gauge their pre-existing values toward teaching. 


\section{Recommendation 3: Faculty Development}

Providing timely and relevant faculty development is a part of the successful adaptation of curriculum revision. As in the case of the current study, faculty development should be based on the needs of faculty and must be applicable and engaging. It should allow collaboration among participants to create camaraderie and shared goals while capitalizing on each faculty participant's expertise and experience. Complexity potentially can slow down the process. As the finding from this study suggests, simplicity and trialability of active learning methodologies were found to be essential to faculty motivation to implement them. It is crucial that faculty development is designed to demonstrate and highlight the ease of usage and simplicity of innovations.

In addition to creating and delivering faculty development that is applicable, engaging, and simple, the change agent should pay close attention to observability and choose faculty development delivery carefully as Rogers (2003) and Parisot (1997) assert the importance of observability of innovation among their immediate sociocultural group - peer group. Rather than hiring educational experts who are not considered as "peer group" of faculty members, having them observe their peers who deliver effective active learning can be a powerful faculty development tool. Moreover, post-curriculum revision faculty development must include a plan for structural way to highlight best practices and celebrate accomplishments.

\section{Future Research}

This study explored intrinsic and extrinsic motivational factors surrounding medical faculty engagement in curricular revisions. Although this study was conducted at 
one institution with a relatively small number of participants, the findings are important as it sheds light pm faculty perspectives that are oftentimes underrepresented in the literature. This section covers potential areas for future research within medical education, surrounding the curriculum innovation and its impact on faculty including motivational factors and change management.

In this study, an intrinsic factor, the relative advantage was found to be an important factor that influenced the adoption of an innovation. However, the study did not investigate the concept of incremental innovation (Rogers 2003). Further research should include faculty perception on curriculum revision and their views on the desired outcome.

To continue to understand curriculum revision implementation at the study site, further study should include interviewing faculty members who fit into other adopter categories such as early majority, late majority, and laggards in order to explore their perceptions which may uncover areas of concern and implications. The comparison between various adopter categories would provide the change agent deeper understanding of the faculty members' views and potentially create a strategic plan to address any issues that are currently suppressed.

Qualitative studies at other medical educational institutions would extend understanding of motivational factors and share best practices surrounding active learning methodologies that are relevant to medical education and development of effective faculty development offerings. In this study, faculty members who were identified as early adopters were interviewed. The future research should explore other adopter 
categories to find similarities and differences in motivational factors among them in order to offer institutions planning to overhaul or revise curriculum diverse perspectives. In addition, in the current study, structural characteristics related to organizational innovativeness were not investigated. The future research should explore the characteristics of an organization such as centralization, complexity, formalization, interconnectedness, organizational slack (Rogers, 2003) at each research study site.

\section{Conclusion}

The United States has the highest health expenditures as a percentage of gross domestic product compared to other industrial nations while health life expectancy at birth is at the lowest and both maternity mortality ratio and under-five mortality rate are at the highest (World Health Statistics, 2019). Medical communities at both national and local levels are responding to this dire state by rethinking various facets of the healthcare system and delivery. In part, in the interest of improving the health-care system, national organizations such as the American Medical Association (AMA) and Association of American Medical Colleges (AAMC) called for a transformation in medical education. They recognize that medical education is only a piece of the puzzle but yet an important one in order to train future physicians and leaders in the field who not only are equipped to deliver excellent patient care but also to improve the future state of the nation's healthcare. Such changes include the implementation of competency-based education and active learning and adding emerging science content areas such as health systems science or patient safety. 
In response, many U.S. medical schools have completed or undergoing curriculum transformation. Curriculum transformation requires faculty participation as they play key roles in all aspects of curriculum revision from development, implementation, and evaluation (Keating, 2014, Thomas, Kern, Hughes, \& Chen, 2016); therefore, engagement from faculty is essential to curriculum transformation. In addition, many literatures suggest faculty have a direct influence on students' success and motivation (Hendrickson and Lane, 2013, Kuh, 2008, Sogunro, 2015, Tinto, 1993, Williams and Williams, 2011). But today's medical education faculty face significant pressure to improve their productivities in clinical and/or research missions. Yet, there are faculty who have risen to the challenges as early adaptors of a new curriculum, taking on roles in implementation new pedagogical approaches to their instruction to promote learner-centered curriculum. Uncovering factors associated with adoption of the new curriculum by faculty shed light on their perspectives. To this end, based on the diffusion of innovation theory (Rogers, 2003), this study examined extrinsic and intrinsic motivational factors that foster medical education faculty to adopt curriculum transformation, specifically learner-centered active learning methodologies. Intrinsic motivational factors such as relative advantage, compatibility, complexity, trialability, and observability all found to have contributed to faculty participants' motivation to partake in curriculum revision. It is interesting to note that none of the faculty participants had learner-centered education through their formal education but all felt congruent with the concept and seemed to have a good grasp of what the role of teachers ought to be. It is important to note that intrinsic motivation played a key role in the 
faculty participants to decision to adopt changes. Their pre-existing belief and understanding of the role of teachers pointed to support the change and their desire to incorporate active learning methods. However, the study found that limitations existed when it comes to a type of active learning methodologies. Despite the change agent's promotional efforts, an active learning method that was perceived as complex and difficult to implement failed to be adopted by the faculty. Simple, easy to try, and observable active learning methodologies, such as clicker questions, concept maps, and think-pair-share were adopted. The Overall findings suggest that five intrinsic motivational factors interrelatedly contributed their decision to participate in the curriculum revision. The current study also examined extrinsic motivational factors. As discussed, most of the faculty participants were not aware of national initiatives or the reasons behind the curriculum revision. As to the type of innovation-decision, although the faculty participants felt that the curriculum revision initiative was top-down, they had the autonomy to participate or not. Another element of extrinsic motivational factors Rogers (2003) discusses is the social system. The current study found that the social system in this institution valued teaching and it was shared amongst the faculty participants' respective departments which in turn fostered the norms that seemed to affect the faculty participants' decision to participate in the curriculum transformation.

In conclusion, the study found that intrinsic motivation factors, specifically congruence of the innovation with their pre-existing belief played a key role in the faculty participants' motivation to participate in the new curriculum and adopt learner-centered active learning methods. In addition, the simplicity of the active learning methods was 
found to be a motivational factor contrary to the one that was perceived as too complex, time-consuming and difficult to implement despite the administration's effort to provide faculty development. The study also found that norms and attitudes toward teaching missions within their respective departments contributed to the faculty participants' motivation to participate in the curriculum revision. The findings from this study can be used by other medical schools that are planning or undergoing curriculum revisions to facilitate transitions. 


\section{References}

AAMC Mission. (n.d.). Retrieved from

https://www.aamc.org/download/330254/data/mission.pdf

AAMC (2018). Curriculum Change in US Medical Schools: Implementation of Change in 2017-2018. Retrieved from https://www.aamc.org/initiatives/cir/427196/27.html

Abdulghani, H. M. (2008). Stress and depression among medical students: A cross sectional study at a medical college in Saudi Arabia. Pakistan Journal of Medical Sciences, 24(1), 12.

ACGME Mission, Vision, and Values. (n.d.). Retrieved from

http://www.acgme.org/acgmeweb/tabid/121/About/Misson,VisionandValues.aspx

AMA (2013). Retrieved from http://www.ama-assn.org/sub/accelerating-

change/overview.shtml

AMA Mission \& Guiding Principles. (n.d.). Retrieved from http://www.amaassn.org/ama/pub/about-ama.page

Appelbaum, S. H., Leblanc, M., \& Shapiro, B. T. (1998). The aftermath of downsizing: A case study of disengagement, disidentification, disenfranchisement and disenchantment. Journal of Management Development, 17(6), 402-431.

Bailey, K. D. (1987). Methods of social research. New York, NY: The Free Press.

Banta, T. W., \& Palomba, C. A. (2014). Assessment essentials: Planning, implementing, and improving assessment in higher education. John Wiley \& Sons. 
Balcioglu, H., Bilge, U., \& Unluoglu, I. (2015). A historical perspective of medical education. Journal of Education in Science, Environment and Health, 1(2), 111114.

Barrows, H. (2006). Problem-based learning in medicine and beyond: A brief overview. New Directions for Teaching and Learning, 1996(68), 3-12.

Bennett, J., \& Bennett, L. (2003). A review of factors that influence the diffusion of innovation when structuring a faculty training program. Internet and Higher Education 6(1), 53-63.

Bergmann, J., \& Sams, A. (2008). Remixing chemistry class. Learning and Leading with Technology, 36(A), 24-27.

Berry, J. (2005). Reclaiming the Ivory Tower. New York, NY: Monthly Review Press.

Berwick, D. M., \& Hackbarth, A. D. (2012). Eliminating waste in US health care. Journal of American Medical Association, 307(14), 1513-1516.

Beck, A. (2004). The Flexner report and the standardization of American medical education. Journal of American Medical Association, 291(17), 2139-2140.

Bender, D. S., \& Weimer, M. (2005). The phenomenology of change: How do individual faculty manage the instructional change process? Online Submission. [Does this refer to a submitted manuscript? If so, change to: Manuscript submitted for publication.]

Blank, R. H. (2012). Transformation of the US healthcare system: Why is change so difficult? Current Sociology, 60(4), 415-426. 
Blumberg, P. (2012). Developing Learner-Centered Teaching: A Practical Guide for Faculty. San Francisco, CA: Jossey-Bass

Bolman, L., \& Deal, T. (2003). Reframing organization: artistry, choice and leadership. San Francisco, CA: Jossey-Bass.

Boyatzis, R. (1998). Transforming qualitative information: Thematic analysis and code development. Thousand Oaks, CA: Sage.

Bridges, W. (2009). Transitions. Philadelphia, PA: Da Capo Press.

Brown, J., \& Nelson, J. (2003). Integration of information literacy into a revised medical school curriculum. Informatics Education, 22(3), 63-74.

Brown, K. L. (2003). From teacher-centered to learner-centered curriculum: Improving learning in diverse classrooms. Education, 124(1), 49-54.

Brownell, S. E., \& Tanner, K. D. (2012). Barriers to faculty pedagogical change: Lack of training, time, incentive, and... tensions with professional identity? CBE-Life Sciences Education, 11(4), 339-346.

Brownlee, S. (2007). Overrated: Why too much medicine is making us sicker and poorer. New York, NY: Bloomsbury.

Bruner, J. (1990). Acts of meaning. Cambridge, MA: Harvard University Press. Bryman, A. (2006) Integrating quantitative and qualitative research: How is it done? Qualitative Research 6(1): 97-113.

Bryman, A. (2008). Social research methods. Oxford, UK: Oxford University Press. Cameron, D. (2001). Working with spoken discourse. London, UK: Sage. 
Carraccio, C., Wolfsthal, S. D., Englander, R., Ferentz, K., \& Martin, C. (2002). Shifting paradigms: From Flexner to competencies. Academic Medicine, 77(5), 361-367.

Chen, C. H., van den Broek, S., \& ten Cate, O. (2015). The case for use of entrustable professional activities in undergraduate medical education. Academic Medicine, 90(4), 431-436.

Clandinin, D. J., \& Connelly, F. M. (2000). Narrative inquiry. San Francisco, CA: Jossey-Bass.

Conger, C. O., Baldwin, J. H., Abegglen, J., \& Callister, L. C. (1999) The shifting sands of health care delivery: Curriculum revision and integration of community health nursing. Journal of Nursing Education, 38(7), 108-113.

Collier, R. (2011). American Medical Association membership woes continue. Canadian Medical Association Journal, 183(11), 713-714.

Commonwealth Fund (2014). Mirror, mirror on the wall, 2014 update: How the U.S. health care system compares internationally. Retrieved from http://www.commonwealthfund.org/publications/fund-reports/2014/jun/mirrormirror

Cooke, M., Irby, D. M., \& O'Brian, B. C (2010). Educating Physicians: A Call for Reform of Medical School and Residency. San Francisco, CA: Jossey-Bass.

Cooke, M., Irby, D. M., Sullivan, W., \& Ludmerer, K. M. (2006). American medical education 100 years after the Flexner report. The New England Journal of Medicine, 355(13), 1339-1344.

Cortazzi, M. (1993). Narrative analysis. Bristol, PA: The Flamer Press. 
Cottingham, A. H., Litzelman, D. K., Frankel, R. K., Williamson, P. R., Suchman, A. L., \& Inui, T. S. (2013). The dissemination of relationship-centered care approaches to enhance the informal curriculum of academic health science centers. In L. A. Headrick \& D. K. Litzelman (Ed.), Educators' stories of creating enduring change (pp. 119-140). New York, NY: Radcliffe Publishing Ltd.

Creswell, J. W. (2003). Research design: Qualitative, quantitative and mixed methods approaches. London: Sage.

Creswell, J. W. (2012). Educational research: planning, conducting and evaluating quantitative and qualitative research. Upper Saddle River, NJ: Pearson.

Crompton, M. (2004). A new curriculum for new age. TechTrends: Linking research \& practice to improve learning, 48(4), 32-34, 36-40, 42-47,

Dancey, M., \& Henderson, C. (2010). Pedagogical practices and instructional change of physics faculty. American Journal of Physics, 78(10), 1056-1063.

Davis, D., O’Brien, M. A., Freemantle, N., Wolf, F. M., Mazmanian, P., \& TaylorVaisey, A. (1999). Impact of formal continuing medical education. Journal of American Medical Association, 282(9), 867-874.

Davis, F. D. (1989). Perceived usefulness, perceived ease of use, and user acceptance of information technology. MIS Quarterly, 13(3), 319-340.

Dillon, G. F., Boulet, J. R., Hawkins, R. E., \& Swanson, D. B. (2004). Simulations in the United States medical licensing examination (USMLE). Quality and Safety in Health Care, 13(1), 41-45. 
Dole, S., Bloom, L., \& Kowalske, K. (2016). Transforming pedagogy: Changing perspectives from teacher-centered to learner-centered. Interdisciplinary Journal of Problem-Based Learning, 10(1), 1. Retrieved from http://dx.doi.org/10.7771/1541-5015.1538

Doyle, T. (2011). Learner Centered Teaching Putting the Research on Learning into Practice. Stylus Publishing.

Duffy, T. (2011). The Flexner Report - 100 years later. Yale Journal of Biology and Medicine, 84(3), 269-276.

Emanuel, E., Tanden, N., Altman, S., Armstrong, S., Berwick, D., de Brantes, F., ...Spiro, T. (2012). A systematic approach to containing health care spending. New England Journal of Medicine, 367(10), 949-954.

Emes, C., \& Cleveland-Innes, M. (2003). A journey toward learner-centered curriculum. Canadian Journal of Higher Education, 33(3), 47-69.

Englander, R., Cameron, T., Ballard, A. J. Dodge, J., Bull, J., \& Aschenbrener, C. A. (2013). Toward a common taxonomy of competency domains for the health professions and competencies for physicians. Academic Medicine, 88(8), 10881094.

Evans, R. E. (1996). The human side of school change. San Francisco, CA: Jossey-Bass.

Farmer, F. A. (2004). Faculty development for problem-based learning. European Journal of Dental Education, (8)2, 59-66.

Faust, J. L., \& Paulson, D. R. (1998). Active learning in the college classroom. Journal on Excellence in College Teaching, 9(2), 3-24. 
Federation of American Societies for Experimental Biology (2014). NIH research funding rebounds in president's FY 2016 budget. Retrieved from http://www.faseb.org/Portals/2/PDFs/opa/2015/2.10.15\%20NIH\%20Funding\%20 Cuts\%202-pager.pdf

Fields, S., Toffler, W., Elliott, D., \& Chappelle, K. (1998). Principles of clinical medicine. Academic Medicine, 73(1), 25-31.

Fink, D. (2003). Creating significant learning experiences: An integrated approach to designing college courses. San Francisco, CA: Jossey-Bass.

Galletta, A. (2013). Mastering the semi-structured interview and beyond from research design to analysis and publication. New York, NY: University Press.

Genthon, M., \& Joscelyn, M. (1989). Why does it take "forever" to revise the curriculum? Accent on improving college teaching and learning, 3. National Center for Research to Improve Postsecondary Teaching and Learning, 2-4.

Gishen, K., Ovadia, S., Arzillo, S., Avashia, Y., \& Thaller, S. R. (2012). The current format and ongoing advances of medical education in the United States. Journal of Craniofacial Surgery, 25(1), 35-39.

Glesne, C. (2016). Becoming qualitative researchers: An introduction (5th ed.). Boston, MA: Pearson.

Green, M. F. (2007). Internationalizing community college: Barriers and strategies. New Directions for Community College, 2007(138), 15-24.

Gormally, S., \& Coburn, A. (2014). Finding nexus: Connecting youth work and research practices. British Educational Research Journal, 40(5), 869-885. 
Goulston, K., Oates, K., Shinfield, S., \& Robinson, B. (2012). Medical student education: what it costs and how it is funded. Internal Medicine Journal, 42(10), 1149-1152.

Guba. E. G., \& Lincoln, Y. A. (2005). Paradigmatic controversies, contradictions, and emerging confluences. In N. K. Denzin \& Y. S. Lincoln (Eds.), The Handbook of Qualitative Research (3rd ed.) (pp. 191-215). Thousand Oaks, CA: Sage.

Guyer, B., Freedman, M. A., Strobino, D. M., \& Sondik, E. J. (2000). Annual summary of vital statistics: Trends in the health of Americans during the $20^{\text {th }}$ century. Pediatrics, 106(6), 1307-1317.

Hertz, R. (1997). Reflexivity and voice. Thousand Oaks, CA: Sage.

Hodges, B. D. (2010). A tea-steeping or i-Doc model for medical education? Academic Medicine, 85(9), 34-44.

Holdcroft, A. (2007). Gender bias in research: how does it affect evidence based medicine? Journal of the Royal Society of Medicine, 100(1), 2-3.

Holmboe, E., Ward, D., Reznick, R., Katsufrakis, P., Leslie, K., Patel, V., ...Nelson, E. (2011). Faculty development in assessment: The missing link in competencybased medical education. Academic Medicine, 86(4), 460-467.

Horowitz, R. (2013). In the public interest-medical licensing and the disciplinary process. New Brunswick, NJ: Rutgers University Press.

Huun, K., \& Hughes, L. (2014). Autonomy among thieves: Template course design for student and faculty success. Journal of Educators Online, 11(2). Retrieved from http://search.ebscohost.com/login.aspx?direct=true\&db=eric\&AN=EJ1033261\&si te=ehost-live 
Hutchinson, S., \& Skodol-Wilson, H. (1992). Validity threats in scheduled semistructured research interviews. Nursing Research, 41(2), 117-119.

Irby, D. M., Cooke, M., \& O’Brien, B. C. (2010). Calls for reform of medical education by the Carnegie Foundation for the Advancement of Teaching: 1910 and 2010. Academic Medicine, (85)2, 220-227.

Issenberg, B. S., McGaghie, W. C., Petrusa, E. R., Gordon, D. L., \& Scalese, R. J. (2005). Features and uses of high-fidelity medical simulations that lead to effective learning: A BEME systematic review. Medical Teacher, 27(1), 10-28.

James, J. (2013). A new, evidence-based estimate of patient harms associated with hospital care. Journal of Patient Safety, 9(3), 122-128.

Jonas, S., Goldsteen, R. L., \& Goldsteen, K. (2007). An introduction to the U.S. healthcare system. New York, NY: Springer Publishing Company.

Jones, R.F., \& Korn, D. (1997). On the cost of educating a medical student. Academic Medicine, (72)3, 200-210.

Kagan, S. (1994). Cooperative learning. San Clemente, CA: Kagan Publishing.

Kalra, J. (2011). Medical errors and patient safety strategies to reduce and disclose medical errors and improve patient safety. Saskatchewan, Canada: Walter de Gruyter.

Kassebaum, D. (1992). Origin of the LCME, the AAMC-AMA partnership for accreditation. Academic Medicine, 67(2), 85-87.

Keating, S. (2014). Curriculum development and evaluation in nursing, Philadelphia: Lippincott. 
Khalil, M. K., \& Kibble, J. D. (2014). Faculty reflections on the process of building an integrated preclerkship curriculum: A new school perspective. Advances in Physiology Education, 38(3), 199-209.

Kilmann, R. H., Saxton, M. J., \& Serpa, R. (1986). Issues in understanding and changing culture. California Management Review, 28(2), 87-94.

Kilroy, D. A. (2004). Problem based learning. Emergency Medicine Journal, 21(4), 411413.

King, E. \& Boyatt, R. (2015). Exploring factors that influence adoption of e-learning within higher education. British Journal of Educational Technology, 46(6), 12721280.

Knowles, M. S., Holton, E. F., \& Swanson, R. A. (2015). The adult learner (8th ed.) New York, NY: Routledge.

Krathwohl, D. R. (2009). Methods of educational and social science research. The logic of methods. Long Grove, IL: Waveland Press.

Kuh, G. (2008). High-impact educational practices: What they are, who has access to them and why they matter. Washington, DC: Association of American Colleges and Universities.

Lawrence, C. M., \& Shinham, K. M. (2015). Enhancing students' learning: Instant feedback cards. American Journal of Business Education, 8(1), 63-70.

LCME Standards, Publications, and White Papers. (n.d.). Retrieved from http://www.lcme.org/publications.htm 
Leape, L. (2000). Institute of medicine medical error figures are not exaggerated. Journal of American Medical Association, 284(1), 95-97.

Leach, D. C. (2001). The ACGME competencies: substance or form? Journal of the American College of Surgeons, 192(3), 396-398.

Ludmerer, K. M. (2004). Learner-centered medical education. New England Journal of Medicine, 351(12), 1163-1164.

Lyness, J. M., Lurie, S. J., Ward, D. S., Mooney, C. J., \& Lambert, D. R. (2013). Engaging students and faculty: implications of self-determination theory for teachers and leaders in academic medicine. BMC medical education, 13, 151.

Maeshiro, R., Johnson, I., Koo, D., Parbooshign, J., Carney, J. K., Gesundheit, N., ...Bennette, N. M. (2010). Medical education for healthier population: Reflections on the Flexner Report from a public health perspective. Academic Medicine, 85(2), 211-219.

Merton, R. K. (1972). Insiders and outsiders: A chapter in the sociology of knowledge. American Journal of Sociology, 78(1): 9-47.

Martyn, M. (2007). Clickers in the classroom: An active learning approach. Educause Quarterly, 30(2), 71-74.

Mayer, R. E. (1998). Cognitive theory for education: What teachers need to know. In N. L., \& B. M. Editor (Eds.), How students learn (pp. 353-377). Washington DC: American Psychological Association.

McLaren, H. J., \& Kenny, P. L. (2015). Motivating change from lecture-tutorial modes to less traditional forms of teaching. Australian Universities' Review, 57(1), 26-33. 
Merriam, S. B., \& Bierema, L. L. (2014). Adult learning: Linking theory and practice. San Francisco, CA: Jossey-Bass

Merriam S. B., Johnson-Bailey, B., Lee M., Kee Y., Ntseane, G., \& Muhamad, M. (2001) Power and positionality: negotiating insider/outsider status within and across cultures. International Journal of Lifelong Education, 20(5), 405-416

Mertens, D. M. (2010). Research and evaluation in education and psychology: Integrating diversity with quantitative, qualitative, and mixed methods. London, UK: Sage.

Michael, J. (2007). Faculty perceptions about barriers to active learning. College Teaching, 55(2), 42-47.

Michaelsen, L. K., \& Sweet, M. (2011). Team-based learning. New Directions for Teaching and Learning, 2011(128), 41-510.

Misch, D. A. (2002). Andragogy and medical education: Are medical students internally motivated to learn? Advances in Health Sciences Education, 7(2), 153-160.

Mitchell, W. J. T. (1989). On narrative. Chicago, IL: Chicago University Press.

Nasca, T. J., Philibert, I., Brigham, T., \& Flynne, T. C. (2012). The net accreditation system-rationale and benefits. The New England Journal of Medicine, 366(11), 1051-1055.

Oakley, B., Felder, R., Brent, R., \& Elhajj, I. (2004). Turning student groups into effective teams. Journal of Student Centered Learning, 2(1), 9-34. 
OECD (2013). Health at a glance 2013: OECD indicators, OECD publishing. Retrieved from http://dx.doi.org/10.1787/health_glance-2013-en

Okuda, Y., Bryson, E. O., DeMaria, S., Jacobson, L., Quinones, J., Shen, B., \& Levine, A. I. (2009). The utility of simulation in medical education: What is the evidence? Mount Sinai Journal of Medicine: A Journal of Translational and Personalized Medicine, 76(4), 330-343.

O’Neill, C.A., Fisher, C.A., \& Newbold, S. K. (2009). Developing online learning envirnoments in nursing education (2nd ed.). New York, NY: Springer Publishing Company.

Osborne, M. L., \& Fields, S. A. (2014). Training physicians for the future US health care system. Future Hospital Journal, 1(1), 56-61.

Papp, K. K., \& Aaron, D. C. (2000). Reflections on academic duties of medical school faculty. Medical Teacher, 22(4), 406-411.

Parisot, A.H. (1997). Distance education as a catalyst for changing teaching in the community college: Implications for institutional policy. New Directions for Community Colleges, 99, 5-13.

Patton, M. (2002). Qualitative research and evaluation methods (3rd ed.). Thousand Oaks, CA: Sage.

Penjor, S., \& Zander, P. (2016). Predicting virtual learning environment adoption: A case study. The Turkish Online Journal of Educational Technology, 15(1), 69-81.

Petri, H. L. (1996). Motivation: Theory, research, and applications. (4th ed.). Pacific Grove, CA: Brooks/Cole Publishing. 
Polkinghorne, D. E. (1995). Narrative configuration in qualitative analysis. International journal of qualitative studies in education, 8(1), 5-23.

Prince, M. (2004). Does active learning work? A review of the research. Journal of Engineering Education, 93(3), 223-231.

Prober, C. G., \& Heath, C. (2012). Lecture halls without lectures - A proposal for medical education. New England Journal of Medicine, 366(18), 1657-1659.

Quillen, D. M. (2001). Challenges and pitfalls of developing and applying a competencybased curriculum. Family Medicine, 33(9), 652-654.

Repetto, M., \& Trentin, G. (2011). Faculty training for web enhanced learning. Hauppauge, NY: Nova Science.

Resnick, L. B. (1989). Introduction. In L. B. Resnick (Ed.), Knowing, learning, and instruction: Essays in Honor of Robert Glaser (pp. 1-24). Hillsdale, NJ: Erlbaum.

Richardson, S.A., Dohrenwend, B. S., \& Klein, D. (1965). Interviewing. New York: Basic Books.

Riessman, C. K. (1993). Narrative analysis. Newbury Park, CA: Sage.

Robert, D., \& Shenhav, S. (2014). Fundamental assumptions in narrative analysis: Mapping the field. The qualitative report, 19(38), 1-17.

Rogers, E. M. (2003). Diffusion of innovations. New York: Free Press.

Ryan, R. M., \& Deci, E. L. (2000). Self-determination theory and the facilitation of intrinsic motivation, social development, and well-being. American Psychologist, 55(1), 54-67. 
Saldana, J. (2015). The coding manual for qualitative research (3rd ed.). New York, NY: Sage.

Schmidt, J. M. (2009). Is homeopathy a science? - Continuity and clash of concepts of science within holistic medicine. Journal of Medical Humanity, 30(2), 83-97.

Schuster, J. H., \& Finkelstein, M. J. (2006). The American faculty: The restructuring of academic work and careers. Baltimore, MD: JHU Press.

Scott, T. M. (2000). Basic science in medical education. Clinical and Investigative Medicine, 23(1), 18-19.

Seligman, M. E. (1972). Learned helplessness. Annual Review of Medicine, 23(1), 407412.

Shaunessay-Dedrick, E., Suldo, S. M., Roth, R. A., \& Fefer, S. A. (2015). Students' perceptions of factors that contribute to risk and success in accelerated high school courses. High School Journal, 98(2), 109-137.

Smith, H. W. (1975). Strategies of social research: Methodological imagination. London, UK: Prentice Hall International.

Sogunro, O. A. (2015). Motivating factors for adult learners in higher education. International Journal of Higher Education, 4(1), 22-37.

Stage, F. K., Muller, P., Kinzie, J., \& Simmons, A. (1998). Creating learning centered classrooms: What does learning theory have to say. Washington, DC: ASHEERIC Higher Education Report.

Steinert, Y., Mann, K., Centeno, A., Dolmans, D., Spencer, J., Gelula, M., \& Prdeaux, D. (2006). A systematic review of faculty development initiatives designed to 
improve teaching effectives in medical education: BEME guide No. 8. Medical Teacher, 28(6), 497-526.

Sutherland, J. M., Fisher, E. S., \& Skinner, J. S. (2009). Getting past denial—-the high cost of health care in the United States. New England Journal of Medicine, 261(13), 1227-1230.

Swilky, J. (1992). Reconsidering faculty resistance to writing reform. WPA: Writing Program Administration, 16(1-2), 50-60.

Swing, S. (2007). The ACGME outcome project: Retrospective and prospective. Medical Teacher, 29(7), 648-655.

Thomas, P, Kern, D., Hughes, M., Chen, B. (2016). Curriculum development for medical education: A six-step approach. Baltimore, MD: Johns Hopkins University Press.

Thompson, B. M., Schneider, V. F., Haidet, P., Levine, R. E., McMahon, K. K., Perkowski, L. C., \& Richards, B. F. (2007). Team-based learning at ten medical schools: Two years later. Medical Education, 41(3), 250-257.

U.S. Census Bureau. (2007, January 12). Demographic trends in the 20th century: Allegany County, N.Y. Retrieved from https://www.census.gov/prod/2002pubs/censr-4.pdf.

Veale, P., Carson, J., Coderre, S., Woloschuk, W., Wright, B., \& McLaughlin, K. (2014). Filling in the gaps of clerkship with a comprehensive clinical skills curriculum. Advances in Health Sciences Edudation, 19(5), 699-707. 
Warren, C. (2006). Incorporating multiculturalism into undergraduate psychology courses: Three simple active learning activities. Teaching of Psychology, 33(2). 105-109.

Weimer, M. (2002). Learner-centered teaching: Five key changes to practice. John Wiley \& Sons.

Wiklund, M., Dwyer, A., \& Davis, E. (2015). Medical device use error: Root cause analysis. Boca Raton, FL: CRC Press.

Wilkerson, L., \& Irby, D. M. (1998). Strategies for improving teaching practices: A comprehensive approach to faculty development. Academic Medicine, 73(4), 387396.

Williams, K. C., \& Williams, C. C. (2011). Five key ingredients for improving student motivation. Research in Higher Education Journal, 12, 1-23.

Williams, R. A. (2011). Healthcare disparities at the crossroads with healthcare reform. Springer Science \& Business Media.

Wong, B. M., \& Holmboe, E. S. (2016). Transforming the academic faculty perspectives in graduate medical education to better align educational and clinical outcomes. Academic Medicine, 91(4), 473-479.

Woolf, S. H., \& Aron, L. Y. (2013a). Findings from a national research council/institute of medicine report. Journal of American Medical Association,309(8), 771-772.

Woolf, S. H., \& Aron, L. (2013b). US health in international perspective: Shorter lives, poorer health. National Academies Press. 
Woollard, B., \& Boelen, C. (2012). Seeking impact of medical schools on health: Meeting the challenges of social accountability. Medical education, 46(1), 21-27.

World Health Organization (2015). World Health Statistics 2015. Retrieved from http://www.who.int/gho/publications/world_health_statistics/WHS2015_Indicator Compendium.pdf?ua $=1$

World Health Organization (2019). World Health Statistics 2019. Retrieved from https://apps.who.int/iris/bitstream/handle/10665/324835/9789241565707eng.pdf?ua=1

Yarnall, L., Toyama, Y., Gong, B., Ayers, C., \& Ostrander, J. (2007). Adapting scenariobased curriculum materials to community college technical courses. Community College Journal of Research and Practice, 31(7), 583-601.

Yoder, J. D., \& Hochevar, C. M. (2005). Encouraging active learning can improve students' performance on examinations. Teaching of Psychology, 32(2), 91-95. 
Appendix A: Development of Interview Questions

Background Information:

How long have you been teaching?

Of that time, how long have you been teaching at this institution?

How did you learn how to teach? Did you receive any formal training in teaching?

\section{Overall Motivation Question:}

What motivated you to become involved in the curricular revision?

Probes:

Did you engage voluntarily or feel pressured to do so?

Were there professional motivators or supporters?

Were there personal motivators?

Did you feel it would be successful (well received by learners and able to achieve session objectives)?

\section{Pedagogical Question:}

Would you please describe the changes that you made to your teaching as part of the new curriculum?

Probes:

Were these changes primarily your own strategies or did you receive guidance on what to do?

Are these changes aligned with (connected to) any educational theories or pedagogical concepts? Or, professional association approaches for teaching and learning?

What elements do you think worked best? How do you know?

What elements do you think were least effective? How do you know?

What future or additional changes do you plan to make to your sessions?

\section{Adaptation of Rogers' Model:}

\section{Intrinsic Factors:}

\begin{tabular}{|l|l|}
\hline Perceived Attributes of Innovations \\
\hline \multirow{4}{*}{$\begin{array}{l}\text { Relative } \\
\text { Advantage }\end{array}$} & $\begin{array}{l}\text { What are the benefits of incorporating the type of learning } \\
\text { methods you just described? }\end{array}$ \\
\cline { 2 - 2 } & $\begin{array}{l}\text { Why is it better than traditional teaching methods, such as simply } \\
\text { to lecture for an hour? }\end{array}$ \\
& $\begin{array}{l}\text { Do you see any advantage of curriculum revision? } \\
\text { Do you find the curriculum revision to be compatible with your } \\
\text { belief? } \\
\text { Have you tested? }\end{array}$ \\
\hline
\end{tabular}




\begin{tabular}{|c|c|}
\hline & What are other colleagues doing? \\
\hline \multirow[t]{3}{*}{ Compatibility } & $\begin{array}{l}\text { For the past century, medical education has based its foundation } \\
\text { on Flexner's report, which placed importance on basic science } \\
\text { curriculum. As many medical schools are going through curricula } \\
\text { revisions, how do you see the role of basic science curriculum in } \\
\text { medical education? }\end{array}$ \\
\hline & $\begin{array}{l}\text { Have you had learner-centered educational experience as a } \\
\text { learner? }\end{array}$ \\
\hline & Can you describe your idea about the role of an instructor? \\
\hline \multirow{3}{*}{ Complexity } & Can you describe what learner-centered education is to you? \\
\hline & Have you had formal training in active-learning methods? \\
\hline & $\begin{array}{l}\text { Do you have any pedagogical approaches you are planning to } \\
\text { implement in the near future? }\end{array}$ \\
\hline Trialability & $\begin{array}{l}\text { When you started to implement active learning methods, did you } \\
\text { first try out something simple, easy to implement? }\end{array}$ \\
\hline Observability & Were there any colleagues who were conducting active learning? \\
\hline
\end{tabular}

\section{Extrinsic Factors:}

\begin{tabular}{|c|c|}
\hline \multirow{2}{*}{$\begin{array}{l}\text { Type of } \\
\text { Innovation- } \\
\text { Decision (Optional, } \\
\text { Collective, or } \\
\text { Authority) }\end{array}$} & $\begin{array}{l}\text { Do you feel that the initiatives to revise curriculum were top- } \\
\text { down or consensus of faculty and administration? } \\
\text { Did you feel any pressure from organization to change the way } \\
\text { you have been doing or to participate in curricular revision? }\end{array}$ \\
\hline & $\begin{array}{l}\text { Was there any pressure from your department or administration } \\
\text { to change the way you teach? }\end{array}$ \\
\hline \multirow{4}{*}{$\begin{array}{l}\text { Communication } \\
\text { Channels }\end{array}$} & $\begin{array}{l}\text { Back in the summer of } 2014 \text {, when the new curriculum was } \\
\text { implemented, how was the change communicated to you? Was it } \\
\text { through your colleagues, through town hall, faculty news feed, } \\
\text { etc.? }\end{array}$ \\
\hline & $\begin{array}{l}\text { Were the reasons to change the curriculum clearly communicated } \\
\text { to you? }\end{array}$ \\
\hline & $\begin{array}{l}\text { How would you describe the communication process and } \\
\text { channels in the institution? }\end{array}$ \\
\hline & $\begin{array}{l}\text { How would you describe the communication process and } \\
\text { channels in your department? }\end{array}$ \\
\hline \multirow{3}{*}{$\begin{array}{l}\text { Nature of the } \\
\text { Social System }\end{array}$} & $\begin{array}{l}\text { How do you see the role of teaching in a health science } \\
\text { university? }\end{array}$ \\
\hline & Is teaching valued in your department? \\
\hline & $\begin{array}{l}\text { Are there any incentives to teach, for example, FTE, monetary } \\
\text { incentives, or status as a teacher? }\end{array}$ \\
\hline
\end{tabular}




\begin{tabular}{|l|l|}
\hline \multirow{4}{*}{$\begin{array}{l}\text { Extent of Change } \\
\text { Agent's Promotion } \\
\text { Efforts }\end{array}$} & $\begin{array}{l}\text { As an institution, do you feel we have a culture that embraces } \\
\text { innovation when it comes to teaching? }\end{array}$ \\
\cline { 2 - 2 } & $\begin{array}{l}\text { How have external organizations such as AAMC, ACGME, and } \\
\text { institution? How important is that influence? }\end{array}$ \\
\cline { 2 - 2 } & $\begin{array}{l}\text { What kind of faculty development, if any, did you receive? } \\
\text { implement new pedagogical methods? }\end{array}$ \\
\cline { 2 - 2 } & $\begin{array}{l}\text { What kind of faculty development do you suggest would be } \\
\text { helpful to you? }\end{array}$ \\
\cline { 2 - 2 } & What are the things administration could do to promote changes? \\
\hline
\end{tabular}


Appendix B: Interview Questions

1. How long have you been teaching?

2. Of that time, how long have you been teaching at this institution?

3. How did you learn how to teach?

- Probe: Did you receive any formal training in teaching?

4. Can you describe what learner-centered education is to you?

5. Have you had learner-centered educational experience as a learner?

6. Can you describe your idea about the role of an instructor?

7. Back in the summer of 2014, when the new curriculum was implemented, how was the change communicated to you? Was it through your colleagues, through town hall, faculty news feed, etc.?

8. Were the reasons to change the curriculum clearly communicated to you?

9. How would you describe the communication process and channels in the institution?

10. How would you describe the communication process and channels in your department?

11. What motivated you to become involved in the curricular revision?

Probes:

- Did you engage voluntarily or feel pressured to do so?

- Were there professional motivators or supporters?

- Were there personal motivators?

12. Do you feel that the initiatives to revise curriculum were top-down or consensus of faculty and administration?

13. Was there any pressure from your department or administration to change the way you teach?

14. Have you had formal training in active-learning methods?

15. Would you please describe the changes that you made to your sessions as part of the new curriculum?

Probes:

- Were these changes primarily your own strategies or did you receive guidance on what to do?

- Are these changes aligned with (connected to) any educational theories or pedagogical concepts? Or, professional association approaches for teaching and learning?

- What elements do you think worked best? How do you know?

- What elements do you think were least effective? How do you know?

- What future or additional changes do you plan to make to your sessions?

- Do you have any pedagogical approaches you are planning to implement in the near future?

16. Did you feel it would be successful (well received by learners and able to achieve session objectives)? 
17. When you started to implement active learning methods, did you first try out something simple, easy to implement?

18 . Were there any colleagues who were conducting active learning?

19. What are the benefits of incorporating the type of learning methods you just described?

20. Why is it better than traditional teaching methods, such as simply to lecture for an hour?

21. What kind of faculty development, if any, did you receive?

22. What resources, if any, were available to you in order to implement new pedagogical methods?

23. For the past century, medical education has based its foundation on Flexner's report, which placed importance on basic science curriculum. As many medical schools are going through curricula revisions, how do you see the role of basic science curriculum in medical education?

24. How have external organizations such as AAMC, ACGME, and AMA influenced the change in medical education at our institution? How important is that influence?

25. How do you see the role of teaching in a health science university?

26. Is teaching valued in your department?

- Probe: Are there any incentives to teach, for example, FTE, monetary incentives, or status as a teacher?

27. As an institution, do you feel we have a culture that embraces innovation when it comes to teaching?

28. What kind of faculty development do you suggest would be helpful to you?

29. What are the things administration could do to promote changes? 
Appendix C: Consent to Participate in Research

\author{
The Portland State University \\ Consent to Participate in Research \\ Medical Faculty Engagement in Curricular Revisions: An Inquiry into Individual and \\ Organizational Factors
}

You are being asked to participate in a research study that is being done by Christine M. Cress, $\mathrm{PhD}$, who is the Principal Investigator and Tomoko Tanikawa, student researcher.

Name of Study: Medical Faculty Engagement in Curricular Revisions: An Inquiry into Individual and Organizational Factors

Researcher: Tomoko Tanikawa

Principal Researcher and Supervisor: Christine M. Cress, PhD, Graduate School of Education, Portland State University

\title{
Description/Purpose of Study
}

This study addresses the question: what factors foster medical education faculty to adopt curriculum changes? Specifically, this study explores both intrinsic and extrinsic factors that contribute to medical faculty engagement in curriculum transformation.

\section{Research Process}

The student researcher will engage in the research process as an interviewer. The interview sessions will take place one-on-one with each volunteer participant (approximately for 60-90 minutes; more if the participant desires). The interview session will be audio-recorded and transcribed for data collection and analysis purpose. The student researcher may also take field notes during the sessions. The transcriptions and notes may be shared with the participants involved in each session. If a participant wishes to rephrase or add to a transcript, even if the accuracy is not in question, the researcher will consider those additions with the participant in order to fully capture the intent of the comments.

\section{Risks or Inconvenience}

There are no physical or psychological risks expected from the interviews. If a participant should become uncomfortable, she or he is free to withdraw from the discussion at any time. Participants are also invite to suggest rephrasing or changes to the transcript if it does not accurately reflect thoughts and feelings, regardless of what was actually said. Benefits of the Study 
There is no monetary benefit from this study. However, participants may provide insights into the limited knowledge on the subject of curriculum revision in the medical school education that will benefit them and possibly others. Through interview process, participants may gain a better understanding of their own perceptions and actions as faculty members.

\section{Confidentiality}

The institution will not be identified in the final report. No participants will be identified by name in the transcripts; each will assume a pseudonym for reporting purposes. No participant will be identified in a report or publication about this study. All references that might link names to participants will be destroyed as soon as the final transcript is completed. Access to individual data is limited to the principal researcher and supervisor only. The Portland State University Institutional Review Board (IRB) that oversees human subject research and/or other entities may be permitted to access your records, and there may be times when we are required by law to share your information. It is the investigator's legal obligation to report child abuse, child neglect, elder abuse, harm to self or others, or any life-threatening situation to the appropriate authorities, and; therefore, your confidentiality will not be maintained.

\section{Right to Withdraw}

Your participation in this study is completely voluntary. You have the right ot choose not to participate or to withdraw your participation at any point in this study without penalty or loss of benefits to which you are otherwise entitled.

If you have any questions during the course of this study, please contact Tomoko Tanikawa (503)494-5100 (office)/tomokotanikawa@ hotmail.com or Dr. Christine Cress (503)725-4682 (office)/cressc@pdx.edu.

If you have any questions about your rights as a human subject, please contact the Portland State University Office for Research Integrity at (503) 725-2227 or 1(877) 4804400. The ORI is the office that supports the PSU Institutional Review Board (IRB). The IRB is a group of people from PSU and the community who provide independent oversight of safety and ethical issues related to research involving human participants. For more information, you may access the IRB website at https://sites.google.com/a/pdx.edu/research/integrity.

\section{CONSENT}

You are making a decision whether or participate in this study. Your signature below indicates that you have read the information provided (or the information was read to you). By signing this consent from, you are not waiving any of your legal rights as a research participant.

You have had an opportunity to ask questions and all questions have been answered to your satisfaction. By signing this consent form, you agree to participate in this study. A copy of this consent form will be provided to you. 
MEDICAL FACULTY ENGAGEMENT IN CURRICULAR REVISIONS

Name of Participant (print) Participant's Signature Date

\section{INVESTIGATOR SIGNATURE}

This research study has been explained to the participant and all of his/her questions have been answered. The participant understands the information described in this consent form and feely consents to participate.

Name of Researcher (print)

$$
\text { Researcher's Signature }
$$

Date 